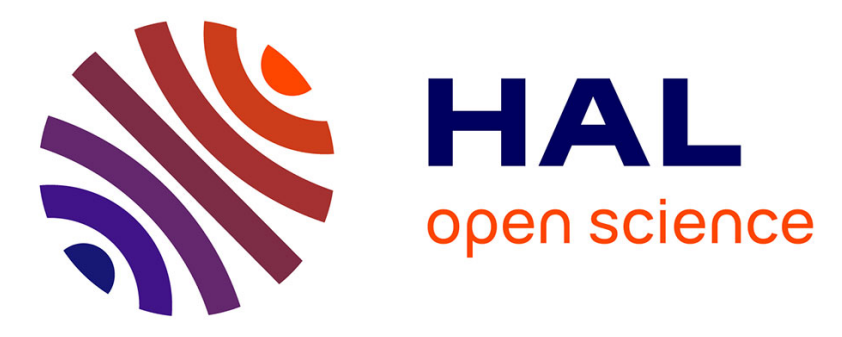

\title{
Glutamatergic pre-ictal discharges emerge at the transition to seizure in human epilepsy.
}

Gilles Huberfeld, Liset Menendez de La Prida, Johan Pallud, Ivan Cohen, Michel Le van Quyen, Claude Adam, Stephane Clemenceau, Michel Baulac, Richard Miles

\section{To cite this version:}

Gilles Huberfeld, Liset Menendez de La Prida, Johan Pallud, Ivan Cohen, Michel Le van Quyen, et al.. Glutamatergic pre-ictal discharges emerge at the transition to seizure in human epilepsy.. Nature Neuroscience, 2011, 10.1038/nn.2790 . hal-00628368

\section{HAL Id: hal-00628368 https://hal.science/hal-00628368}

Submitted on 3 Oct 2011

HAL is a multi-disciplinary open access archive for the deposit and dissemination of scientific research documents, whether they are published or not. The documents may come from teaching and research institutions in France or abroad, or from public or private research centers.
L'archive ouverte pluridisciplinaire HAL, est destinée au dépôt et à la diffusion de documents scientifiques de niveau recherche, publiés ou non, émanant des établissements d'enseignement et de recherche français ou étrangers, des laboratoires publics ou privés. 


\title{
Glutamatergic pre-ictal discharges emerge at the transition to seizure in human epilepsy
}

\author{
Gilles Huberfeld 1,2,3, Liset Menendez de la Prida 1,4, Johan Pallud 1.5, \\ Ivan Cohen 1, Michel Le Van Quyen 7, Claude Adam 2, \\ Stéphane Clemenceau 1,2,6, Michel Baulac 1,2 \& Richard Miles 1.
}

1: Cortex and epilepsy, CRICM, INSERM UMRS975, CNRS UMR7225, UPMC, Paris, France

2: Unité d'Epileptologie, CHU Pitié-Salpêtrière, AP-HP, Paris, France

3: Département de Neurophysiologie, UPMC, CHU Pitié-Salpêtrière, Paris, France

4: Laboratorio de Circuitos Neuronales, Instituto Cajal, CSIC, Madrid, Spain

5: Service de Neurochirurgie, Centre Hospitalier Ste Anne, Université Paris Descartes

6: Service de Neurochirurgie, CHU Pitié-Salpêtrière, AP-HP, Paris, France

7: Network dynamics and cellular excitability, CRICM, INSERM UMRS975, CNRS

UMR7225, UPMC, Paris, France

Running Title: Transition to ictal activity in human epileptic tissue.

Keywords: epilepsy, ictogenesis, GABA, glutamate, subiculum, human

Corresponding author:

Richard Miles or Gilles Huberfeld

'Cortex \& Epilepsie' - CR Institut du Cerveau et de la Moelle épinière

INSERM UMRS 975 - CNRS UMR 7225

UPMC - Faculté de Médecine Pitié-Salpêtrière

105 Bd de l'Hôpital - 75013 Paris - France

Tel: +33 (0) 140778165

richard.miles@upmc.fr

gilles.huberfeld@upmc.fr 


\section{ABSTRACT}

Mechanisms involved in the transition to an epileptic seizure remain unclear. We studied this question in tissue slices from human subjects with mesial temporal lobe epilepsies. Ictal-like discharges were induced in the subiculum by increasing excitability together with an alkalinization or low $\mathrm{Mg}^{2+}$. During the transition, distinct pre-ictal discharges emerged concurrently with interictal events. Intracranial recordings from the mesial temporal cortex of epileptic subjects revealed similar discharges before seizures were restricted to seizure onset sites. In vitro, pre-ictal events spread faster, have a larger amplitude and a distinct initiation site than interictal discharges. They depend on glutamatergic mechanisms and are preceded by pyramidal cell firing, while interneuron firing precedes interictal events which depend on both glutamatergic and depolarizing GABAergic transmission. Once established, recurrence of these pre-ictal discharges triggers seizures. Thus the subiculum supports seizure generation and the transition to seizure involves a novel, emergent glutamatergic population activity. 


\section{INTRODUCTION}

Epilepsy is a dynamic disease where ictal events, the clinical manifestation of the pathology, paroxysmally interrupt an interictal state. In EEG records, interictal events are synchronous neuronal discharges of duration tens of milliseconds, while ictal events, or seizures, are patterned discharges that last for several tens of seconds. Interictal discharges reflect pathologic changes in an epileptogenic brain 1,2, but it is unclear whether they trigger or prevent ictal-like activities ${ }^{3}$. The biological basis of the transition from the interictal state to a seizure, or ictogenesis, is poorly understood although seizure onset seems to be preceded by subtle clinical, metabolic and electrical changes ${ }^{4}$.

Different mechanisms and even different neuronal populations may be involved in the genesis of interictal and ictal-like events in the epileptic temporal lobe. In vitro data suggests that interictal events are generated in the CA3 region while seizures may emerge from the entorhinal cortex 5, 6 . Interictal population bursts depend on functionally excitatory signaling 5,7 . Depolarizing responses to GABA may be involved in the genesis of ictal events since several convulsants trigger strong interneuron firing and the enhanced GABA release 8 could switch responses towards depolarization 9, 10, 11. Changes in excitatory synaptic mechanisms may also be involved in the transition to seizure-like activity 12,13 . Several studies suggest that the initiation, properties and propagation of population activities generated by epileptic networks are modified before ictal-like activity is initiated 14-16.

In much of this work, ictal-like activity has been induced by applying convulsants to healthy tissue slices. This approach may miss some aspects of the disease because an epileptic brain differs from healthy tissue. Synaptic connectivity is changed, glial cells are activated and the expression of voltage-gated and transmitter operated channels alters. Another change is an alteration in $\mathrm{Cl}$ - homeostasis in tissue from persons with pharmacoresistant temporal lobe epilepsies. The neurotransmitter GABA has depolarizing effects 1, due in part on a reduced expression of the $\mathrm{K}-\mathrm{Cl}$ co-transporter $\mathrm{KCC} 2$ as well as persistent activity of its counterpart $\mathrm{NKCCl}^{2}$, which contribute to interictallike activity generated by the subiculum.

In this study, we explored the transition from the interictal state to ictallike activity in the subiculum of humans with mesial temporal lobe epilepsy. Seizures were induced in slices of this tissue by combining alkalosis or low $\mathrm{Mg}^{2+}$ with an increase in cellular excitability. During the transition to ictal-like discharges both in slices and in situ, we detected a novel form of population activity- pre-ictal population bursts. These larger amplitude synchronous events co-exist with interictal events. They are mediated by glutamatergic signaling and are preceded by pyramidal cell firing while interneuron discharges consistently precede interictal events which depend on both GABAergic and glutamatergic signaling. Pre-ictal discharges involve more cells and spread faster than do interictal events. Their emergence just before 
ictal-like events raises the possibility that they may be involved in ictal initiation. Indeed, the ability of electrically induced pre-ictal discharges to trigger seizures at their onset sites further supports this hypothesis. 


\section{RESULTS}

\section{Induction of ictal-like events in the epileptic subiculum.}

The subiculum generated a spontaneous interictal-like activity in all experiments 1.2. This activity was transformed into ictal-like discharges in 95/121 slices from 33/42 subjects, by combining two pro-convulsant stimuli (Fig. 1). They combined (Supplementary Table): stimulus 1) a change of extracellular $\mathrm{K}^{+}$from 4 to $6-8 \mathrm{mM}$ ( $\mathrm{n}=31$ epileptic subjects) or a reduction of external $\mathrm{Ca}^{2+}$ and $\mathrm{Mg}^{2+}$ from 2 to $0.5 \mathrm{mM}(\mathrm{n}=11)$ with, stimulus 2) a reduction of external $\mathrm{Mg}^{2+}$ to $0.25 \mathrm{mM}(\mathrm{n}=20)$ or an external alkalinisation imposed by increasing $\mathrm{HCO}_{3}$ - from 25 to $65-85 \mathrm{mM}$ with a concomitant reduction in $\mathrm{NaCl}$ to $85-65 \mathrm{mM}(\mathrm{n}=22)$. Treatments with single convulsants including 4-AP $(n=4)$, bicuculline $(\mathrm{n}=4)$, high $\mathrm{K}^{+}(\mathrm{n}=4)$ or zero $\mathrm{Mg}^{2+}(\mathrm{n}=4)$ were ineffective.

Ictal discharges were recorded from a region of $\sim 2 \times 8 \mathrm{~mm}$ in the subiculum. They propagated towards, but not into, the sclerotic CA 1 region and the presubiculum (Fig. 1a). Ictal-like activity was not recorded from the dentate gyrus, CA3 region or entorhinal cortex although multi-unit activity in these areas was increased by the convulsants.

The mean duration of ictal-like events was $20.7 \pm 1.7$ seconds $195 \%$ confidence interval, $\mathrm{Cl}$ : [19.9-21.5], $\mathrm{n}=16)$. It was similar for different convulsants: high- $\mathrm{HCO}_{3}^{-}$/ high- $\mathrm{K}^{+}(21.4 \pm 9.4 \mathrm{~s}$, median=18.21, range [14.839.8], $\mathrm{n}=6$ ), high $-\mathrm{HCO}_{3}-$ / $\mathrm{low}_{-} \mathrm{Ca}^{2+}-\mathrm{Mg}^{2+}$ (19.8 $\pm 7.0 \mathrm{~s}$, median=20.1, range:

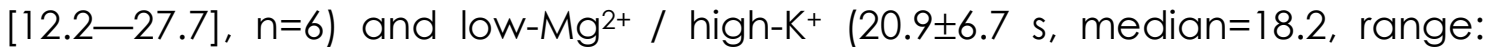
[16.0-31.1], $\mathrm{n}=4$ ) (no significant difference, Kruskal-Wallis variance analysis: $\left.\chi^{2}(2)=4.16, P=0.12\right)$. Once initiated, ictal-like events recurred as long as the convulsant solution was perfused. The mean interval between them was 121.1 \pm 5.2 s (95\% Cl: [1 18.5-123.7], $n=15)$. Exclusive interictal-like activity was restored when the convulsant solution was withdrawn.

Ictal-like field potentials were similar to intracranial EEG records of mesial temporal lobe seizures in humans 17,18 and animals ${ }^{19}$. In slices from 20 individuals they consisted of recurrent rhythmic bursts of frequency $3.7 \pm 0.1 \mathrm{~Hz}$ (95\% Cl: [3.6-3.7]). In slices from 9 subjects, seizure onset involved an initial fast, low-voltage activity (duration $4.1 \pm 0.2$ seconds (median $=4.4$, range: [1.67.3], $n=8$ ), mean frequency of multiunit activity $268.3 \pm 2.6 \mathrm{~Hz}$ (median=275.1, range: [138.9-370.5], $n=8$ ) which evolved into rhythmic bursts (Fig. 1b).

Ictal-like discharge pattern did not depend on the convulsant. Alkalinization was associated with rhythmic bursts in $65 \%$ and with low voltage fast activity in $35 \%$ of experiments $(n=17)$. In low- $\mathrm{Mg}^{2+}$ experiments, rhythmic bursts were observed in $75 \%$ and low-voltage fast activity in $25 \%$ of cases (corrected $\chi^{2}=0.03, \mathrm{P}=0.86$ ). In tissue from 3 persons, similar patterns of ictal-like activity were induced by either low-Mg ${ }^{2+}$ or alkalinization, together with an increased $\mathrm{K}^{+}$(data not shown). 


\section{Pre-ictal discharges precede ictal-like events in vitro.}

Ictal-like events were preceded by recurring population events of larger amplitude than interictal discharges (IID) (Fig. 1b). These pre-ictal discharges (PID) recall 'hypersynchronous' EEG events that precede intracranially recorded temporal lobe seizures $17,18$.

PID recurred during 12.2 \pm 1.5 seconds (95\% Cl: [11.4-13.0], $n=15$ ) before ictal-like events. Their mean frequency was $2.3 \pm 0.2 \mathrm{~Hz}(95 \% \mathrm{Cl}$ : [2.2-2.4], $n=13$ ). PID preceded seizure initiation in $7 / 7$ low voltage fast activity onset and 12/15 rhythmic burst onset ictal patterns, recurring for a similar period at similar frequency (non parametric Spearman correlation, $n=15$ seizures, $\rho=-0.09$, $\mathrm{p}=0.76$ and $\mathrm{n}=13$ seizures, $\rho=-0.60, \mathrm{p}=0.4$ respectively). PID were easily distinguished from the onset of seizures with fast low-voltage activity. Changes in burst frequency and shape usually permitted them to be distinguished from the start of ictal-like events consisting of rhythmic bursts although their onset could be more progressive. These data show that ictal-like activities are generated by the subiculum and preceded by specific pre-ictal events.

\section{In situ records of pre-ictal discharges.}

We searched for similar events in intracranial EEG records from the mesial temporal lobe 20 of persons with epilepsies associated with hippocampal sclerosis. Scalp recordings do not sample activity from these regions unless they propagate to the lateral neocortex. In all 5 subjects studied, seizures emerged from a single zone. With a $1 \mathrm{~cm}^{3}$ resolution for stereoEEG electrodes 21, this zone should encompass the hippocampal formation (subiculum and head of the hippocampus), the amygdala and the entorhinal cortex. Recurring field events similar to PID preceded seizure onset in 9/9 seizures from 5 subjects (Fig. 2a,b, pink circles). PID-like events formed a separate population of events that were larger than IID (Fig. 2a,c, blue circles). The mean amplitude of PID in vivo was $358 \pm 18 \mu \mathrm{V}(95 \% \mathrm{Cl}$ : [355-361], $\mathrm{n}=7754$ PID detected by a restrictive threshold algorithm from 5 in situ records), while that of IID was $140 \pm 19 \mu \mathrm{V}$ (95\% Cl: [137-143], $\mathrm{n}=37483$ IID from 5 records) (Mann-Whitney, $\mathrm{p}<0.001$ ). The mean duration of PID was $203 \pm 12 \mathrm{~ms}$ (95\% Cl: [201-205], $n=7754)$ and that of IID was $185 \pm 6 \mathrm{~ms}$ (95\% Cl: [181-189], $\mathrm{n}=37483$ ) (Mann-Whitney, $\mathrm{p}=0.280$ ) (Fig. 2c,d). In situ, PID were restricted to the hippocampal formation while IID spread to adjacent temporal cortex (Fig. 2b,d). PID were recorded from electrodes that detected fast, low voltage discharges during seizure initiation and were never detected at distances greater than $10 \mathrm{~mm}$ from seizure initiation sites. PID preceded all 9 seizures studied from 5 in situ recordings. We detected $11 \pm 4$ PID in the $30 \mathrm{~s}$ 
before seizure onset (median=10.5, range: [2-25], $\mathrm{n}=6$ seizures). Thus PID occur in the human at seizure initiating sites, especially before seizure onset.

\section{PID emerge during the transition to the ictal state.}

PID emerge at the transition from the interictal to the ictal state (Fig. $3 a, b)$. In vitro, this transition occurred over 29.1 12.2 minutes (median=25.5, range: [13-52], $\mathrm{n}=8$ slices) after convulsant application (Fig. 3a). The delay to the first ictal event was $24.7 \pm 11.5 \mathrm{~min}$ for increased $\mathrm{HCO}_{3}^{-}$/ high- $\mathrm{K}^{+}$ (median=25, range: [13-36], $\mathrm{n}=3$ ), $32.0 \pm 8.5$ min for increased $\mathrm{HCO}_{3}{ }^{-} /$low-

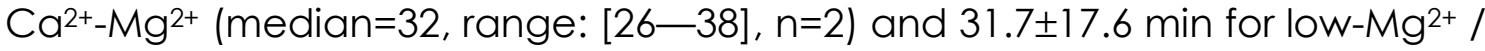
high $-K^{+}$(median=22, range: [21-52], $n=3$ ) (no significant difference, KruskalWallis analysis: $\left.\chi^{2}(2)=1.11, \mathrm{P}=0.57\right)$.

During the transition to ictal activity, PID emerged as field potentials of progressively increasing amplitude, concurrent with IID (Fig. 3a-d). As population activity increased, the amplitude of PID increased while that of IID remained constant (Fig. 3b). The amplitude of stable PID $(185 \pm 106 \mu \mathrm{V}, 95 \% \mathrm{Cl}$ : [146-196], $n=66$ events from 8 slices) was significantly higher than that of simultaneous IID $(49 \pm 24 \mu \mathrm{V}, 95 \% \mathrm{Cl}$ : [42-55], $\mathrm{n}=66$ events from 8 slices) (Wilcoxon test, $Z(7)=3.99, P<0.01$ ) (Fig. 3e). The duration of PID $(83 \pm 48 \mathrm{~ms}, 95 \%$ $\mathrm{Cl}$ : [69-93], $\mathrm{n}=8$ slices) was similar to IID $(77 \pm 34 \mathrm{~ms}, 95 \% \mathrm{Cl}$ : [63-82], $\mathrm{n}=8$ ) (Wilcoxon test, $Z(7)=0.34$, $P=0.75$; Fig. 3e).

PID and IID possessed different spatial and temporal attributes. The spatial extent of PID, along the longitudinal axis of the subiculum, was larger than that of IID (Fig. 3f). The propagation velocity of PID was $0.33 \pm 0.19 \mathrm{~m} / \mathrm{s}$ (95\% Cl: [0.29-0.37], $\mathrm{n}=92$ events from 3 subjects) while that of IID was $0.10 \pm 0.09 \mathrm{~m} / \mathrm{s}$ (95\% Cl: [0.08-0.12], $\mathrm{n}=91$ events from 3 subjects) (t test, $t=10.59, p<0.001)$. Thus PID emerging during the transition to ictal-like discharges, involve more widely distributed groups of neurons than do IID, produce larger fields and spread faster. We next compared their cellular and synaptic basis.

\section{Distinct properties of PID and IID.}

Intracellular records from subicular pyramidal cells (Fig. 4) suggested PID and IID depend on distinct signaling mechanisms. In records from 14 cells in which IID were associated with hyperpolarizing synaptic events 1,2, PID were always accompanied by a depolarization (Fig. 4a). The absence of an hyperpolarization, suggests that GABAergic signaling, necessary for IID I, could be less important in generating PID ${ }^{13}$. Indeed, the $\mathrm{GABA}_{A}$ receptor antagonists bicuculline $(20 \mu \mathrm{M}, \mathrm{n}=6)$ and picrotoxin $(50 \mu \mathrm{M}, \mathrm{n}=3)$ suppressed IID but not PID (Fig. 4b,c and Suppl Fig. 1b). PID amplitude was $310 \pm 167 \mu \mathrm{V}$ (95\% Cl: [121-499], $\mathrm{n}=26$ events from 3 slices) before, and $296 \pm 123 \mu \mathrm{V}(95 \%$ 
Cl: [156-435], $\mathrm{n}=26$ ) after applying $20 \mu \mathrm{M}$ bicuculline. Their duration was 69 \pm 37 (95\% Cl: [27-112], $\mathrm{n}=26$ ) ms before, and 86 $\pm 58 \mathrm{~ms}$ (95\% Cl: [20-152], $\mathrm{n}=26$ ) after bicucculine. Neither parameter changed significantly (Wilcoxon test, $Z(3)=0.57, P=0.63$ for amplitude and $Z(3)=0.48, P=0.68$ for duration). Once established, PID were not affected by blocking NMDA receptors ( $n=6$, Fig. 4b,5b and Suppl Fig. 1c) but were suppressed by the AMPA receptor antagonist $N B Q X,(10-20 \mu M, n=6$, Fig. 4b and Suppl Fig. 1d).

These data show that subicular circuits generate two forms of synchrony during the transition to ictal-like activity: IID depend on glutamatergic and GABAergic signaling while PID seem to be glutamatergic. To confirm this hypothesis, we compared the voltage dependence of compound synaptic potentials associated with both events (Fig. 4c). Synaptic events associated with IID reversed at $-59.1 \pm 3.8 \mathrm{mV}$ while the reversal potential of events associated with PID was estimated as $-15.1 \pm 5.9 \mathrm{mV}$ ( $\mathrm{n}=3$ cells). Further, distinct glutamatergic circuits seem to become effective when cellular excitability increases. In support of this hypothesis, PID emerged in addition to IID when external $\mathrm{K}^{+}$was increased from 4 to $10 \mathrm{mM}$. Ictal events were not triggered in high $\mathrm{K}^{+}$, suggesting that PID do not suffice for seizure initiation $(\mathrm{n}=10$; Fig. 4d).

Moreover, the progressive emergence of PID and the long delay before the first ictal event suggest some cellular or synaptic plasticity could be involved. In the same slices, the delay to a new plateau spike frequency in entorhinal cortex, which does not generate PID, after applying convulsant ( $\mathrm{n}=7,0.25 \mathrm{Mg}^{2+} / 8 \mathrm{~K}^{+}$solution) was $33.3 \pm 11.5 \mathrm{~min}$ (median=34.1, range: [16.248.0], $n=7$ ) while the delay to full amplitude PID in the subiculum was $52.2 \pm 18.8$ min (median=52.1, range: [27.6-73.9.2], $n=7$ ) (Suppl. Fig. 2, $n=7, \dagger$ test, $\dagger=4.48$, $\mathrm{p}<0.01$ ). This difference suggests that processes distinct from an increase in excitability, possibly involving NMDA dependant plastic changes 22 , could be involved in the transition to ictal activity. Established PID were not affected by the NMDA receptor antagonist D-L-APV $(100 \mu \mathrm{M}, \mathrm{n}=6$, Fig. 4b,5b and Suppl Fig. 1c). However, we found that neither PID nor ictal events were generated if D-L-APV was applied before the convulsant, (low-Mg ${ }^{2+} /$ high- $\mathrm{K}^{+}, \mathrm{n}=5$, Fig. 5a). These data suggest that the activation of NMDA receptors, during population bursts, is needed for the emergence, but not maintenance of PID.

Furthermore initiation of ictal events appears to depend on recurring established PID but requires functional GABAergic and glutamatergic signaling since they were suppressed by antagonists at GABA $A_{A}$ or AMPA and NMDA glutamate receptors ( $n=6,4 \& 4$ respectively; Suppl Fig. 1 ).

\section{Synaptic networks underlying IID and PID.}

If different transmitter systems are involved, then different cell types might discharge as IID and PID are initiated. We examined this point using action potential shape 23 to discriminate between pyramidal cells and 
interneurons in juxta-cellular recordings 24 . Action potential duration in 6/45 recorded neurons was less than $0.7 \mathrm{~ms}$ and these cells were classified as interneurons (Fig. 6b; mean duration $0.47 \pm 0.17 \mathrm{~ms}, 95 \% \mathrm{Cl}$ : [0.33-0.61], $\mathrm{n}=6$ ). In 39 putative pyramidal cells, spike duration was greater than $0.7 \mathrm{~ms}$ (Fig. 6a, mean $0.99 \pm 0.20 \mathrm{~ms}, 95 \% \mathrm{Cl}$ : [0.92-1.05], $\mathrm{n}=39$ ).

We then sought to distinguish between cells that fired before PID or IID related field potentials, reasoning that they could be involved in their initiation, and other cells that fired during events or did not fire (Fig. 6, $10 \mathrm{mM}$ $\mathrm{K}^{+}, 10$ subjects). Most pyramidal cells were inhibited during IID (26/39) but almost all of them (37/39) fired during PID (Chi-2, $p<0.0001$; Fig. 6a left). A subset of pyramidal cells (7/39) increased firing in the $25 \mathrm{~ms}$ before the onset of PID field potentials (19 $\pm 26 \mathrm{~Hz}, 95 \% \mathrm{Cl}$ : [9-28], $\mathrm{n}=30$ events from 3 cells; Fig. 6a right). 6/7 of these triggering pyramidal cells were located in the region where PID were initiated and only $1 / 7$ in areas to which PID propagated. Firing during PID was detected for 18/24 cells of the focus, compared to $12 / 15$ in propagation zones (Fisher's exact test, $\mathrm{p}=0.22$ ). None of the pyramidal cells that fired before PID discharged before IID ( $3 \pm 5 \mathrm{~Hz}, 95 \% \mathrm{Cl}$ : [1-5], $\mathrm{n}=3$ cells). In contrast, all recorded interneurons (6/6) discharged during both IID 1 and PID. All 6 cells fired for at least $25 \mathrm{~ms}$ before IID initiation (Fig. $\mathbf{6 b}$ left), but only 2 interneurons fired in the $25 \mathrm{~ms}$ preceding PID initiation (Fig. 6b right). Effective interneuron firing frequency in the $25 \mathrm{~ms}$ before IID onset was $77 \pm 12$ $\mathrm{Hz}$ (95\% Cl: [72-81], n=30 events from 3 cells) and 22 $\pm 13 \mathrm{~Hz}$ (95\% Cl: [17-27], $\mathrm{n}=3$ cells) in the $25 \mathrm{~ms}$ preceding PID. These data suggest that interneurons may be involved in IID initiation (6/6 interneurons fired before IID vs 0/39 pyramidal cells (Fisher's exact test, $p<0.0001)$ ). A majority of pyramidal cells are silent during IID but most of them fire during PID. Among them, a subgroup firing systematically before PID may be involved in their initiation 10/39 pyramidal cells fired before IID $-7 / 39$ fired before PID (Fisher's exact test, $\mathrm{p}=0.01)$ ).

\section{Dynamics and propagation of IID and PID.}

The timing of IID and PID suggested that the circuits generating them were somewhat distinct. An IID was never initiated during a refractory period of $\sim 200 \mathrm{~ms}$ after a PID. Apart from that interaction, PID amplitude and frequency were independent of IID occurrence. Similarly, neither the amplitude nor the timing of IID were affected by a PID ( $n=5$ slices; Suppl Fig. 3 and Fig. 4a).

Dynamic analysis of field potentials generated at distinct sites during the initiation of ictal-like activity demonstrated further differences between PID and IID. We measured the time delay and amplitude and used an index of cross correlation to compare PID and IID recorded by pairs of electrodes separated by $1-2 \mathrm{~mm}$ in slices from 6 different epileptic subjects (Fig. $\mathbf{7 a - d}$ ). 
Both the amplitude and cross correlation index were larger for PID than for IID. Furthermore latencies between PID recorded at different sites were shorter and less variable than those for IID which were often initiated from several foci. At the transition to ictal-like discharges, the latencies of field events recorded from separated electrodes was further reduced, indicating a faster propagation (Fig. 7c,d).

Finally we asked whether PID, which recurred before seizure onset, could effectively initiate seizures. One test of this point is to examine the effects of blocking PID on seizure occurrence but blocking PID with AMPA receptor antagonist also blocked ictal events (Suppl Fig. 1). Another test is to initiate sequences of PID by focal stimulation and to look whether it reliably induces seizures shortly after their generation.

We found single low-intensity stimuli (3-6 V, $0.05 \mathrm{~ms}$ ) delivered near the PID initiation site initiated a similar event (Fig. 8b; $n=7$ slices). Attempting to mimic PID timing, we then tested the effects of $1-2 \mathrm{~s}$ sequences of $2-5 \mathrm{~Hz}$ stimuli. PID sequences induced in this way, triggered seizures in 38/45 trials at PID onset site ( $n=7$ slices), Fig. 8b). Similar low intensity, sequences were never effective at sites of propagation (0/25 trials, Fig. 8c) (Fisher's exact test, $\left.\mathrm{p}<5 \times 10^{-13}\right)$. High intensity stimulation of remote regions $(15-50 \mathrm{~V}, 0.05 \mathrm{~ms})$ could initiate back-propagated PID-like events at PID onset sites. Sequences of these events also triggered ictal-like events $(n=13 / 20$ trials in 3 slices, Fig. 8d). The duration of stimulus-induced ictal-like events was similar to that of spontaneous events (Friedman's $\chi^{2}(2), p=0.26$ ). The pre-ictal period, defined as the time during which PID occurred, was shortened by stimulation induced PID. For spontaneous ictal-like events it was $10.61 \pm 11.35 \mathrm{~s}(95 \% \mathrm{Cl}$ : [10.3410.88], $n=39$ events, 4 slices). For events induced by stimulation at the PID initiation site, the delay was $1.97 \pm 0.53 \mathrm{~s}$ (95\% Cl: [1.96-1.98], $\mathrm{n}=45$ events, 4 slices) and it was longer, 10.39 $\pm 8.44 \mathrm{~s}$ (95\% Cl: [10.19-10.59], $\mathrm{n}=25$ events, 4 slices), for events induced by stimulation at follower sites (Friedman's $\chi^{2}(1)$, $p<0.01)$. The duration of the pre-ictal period, normalized to that of spontaneous ictal events was shorter for stimulation at PID foci than at distant sites $\left(0.28 \pm 0.13\right.$ vs $1.09 \pm 0.5$, Friedman's $\left.\chi^{2}(1), p<0.01\right)$. These data show that the site of PID initiation is a privileged zone for seizure initiation by stimuli that mimic clusters of PID. 


\section{DISCUSSION}

Our data show that the subiculum generates ictal-like activity in tissues from human subjects with temporal lobe epilepsies. Seizures are preceded by a specific form of population activity: pre-ictal discharges emerge during the tens of minutes transition period to seizure and further trigger seizures by recurring in the seconds preceding their onset. Similar events are present at the seizure onset zone in intracranial recordings made from people with TLE. During ictogenesis, PID occur contemporaneously with IID. In situ they are restricted to sites of seizure initiation while IID are more widespread. PID are associated with larger field potentials than IID, suggesting that they involve more neurons, and they propagate more quickly. They depend on glutamatergic rather than the mixed depolarizing GABA/glutamatergic mechanisms underlying IID and are preceded by pyramidal cells firing rather than by interneurons. This novel population activity may be a crucial feature of ictogenesis, and contributes to define both spatial and temporal aspects of seizure initiation.

We found in vitro that different convulsant treatments induced seizurelike activities similar to intracranial records of ictal events from the same patients. Ictal-like activities sometimes included an early period of fast low voltage oscillations, or could consist of rhythmic population bursts. Both patterns were preceded by PID. In situ, these distinct patterns are suggested to depend on different contributions from hippocampus and cortex 25, but our records show an isolated subiculum supports both patterns. Although intracranial macro-electrodes may not possess sufficient spatial resolution to distinguish entorhinal cortex and subicular activity 21, microelectrode records suggest at least interictal activities are generated in the subiculum 26, 27. Our data now show that the subiculum alone can generate ictal-like activity. In previous slice work on human tissue, ictal activities have also been induced in the dentate gyrus by high-K+28, 29 and in neocortical dysplasias by 4-AP 30 .

In vitro, PID emerge during a long transition period before ictal-like events are initiated and recur in the seconds preceding seizure onset. Intracranial EEG records also reveal large amplitude field potentials just before a seizure 31,32. Here we show they are restricted to electrodes sampling the seizure onset zone. Similar field potentials of larger amplitude precede ictal events in several in vitro models of epilepsy 6, 14, 33-35. Moreover, intracranial recordings show PID-like events preceding seizures in multiple focal human epilepsies originating in temporal 17 or extra temporal 36; hippocampal 17, 18 or neocortical 37 regions, and associated with sclerosis 17, 38, malformation ${ }^{39}$, dysplasia or in macroscopically normal tissue ${ }^{36}$.

PID and IID differ pharmacologically. IID depend on both glutamatergic and depolarizing GABAergic signaling ${ }^{1}$ and our data show interneuron firing 
reliably precedes IID initiation (Fig. 6). In contrast PID apparently depend on glutamatergic synapses. They were blocked by AMPA receptor antagonists, reversed at depolarized potentials and were preceded by discharges in a subset of pyramidal cells near their initiation site ${ }^{40}$. Presumably recurrent excitatory synapses between subicular pyramidal cells are responsible ${ }^{41}$. The existence of distinct groups of initiating cells may explain both the contemporaneous generation of PID and IID and the weak temporal interactions between them (Suppl. Fig. 3). A glutamatergic basis, does not exclude an interneuronal participation in PID. However, both the voltage dependence of synaptic events (Fig. 4) and the timing of interneuron firing (Fig. 6) suggest GABAergic systems are secondarily activated compared to IID. A reduced inhibitory restraint could account for the differences in propagation velocity 42 and size of the neuronal population involved in PID and IID (Fig. 3). Excitatory field events similar to PID have been detected just before seizures in animal models $6,8,15,43,44$. PID do not involve barrages of hyperpolarizing synaptic events which may act as an inhibitory restraint, to protect against the spread of seizure-like activities ${ }^{45}$. PID described here differ in that they are initiated near the site of seizure onset in epileptic subiculum rather before events spreading through healthy cortex in the presence of convulsants. PID seem to depend on firing in principal cells with a late interneuron discharge, in contrast to the early interneuron firing that generates a strong feedforward inhibition to restrain seizure spread.

We have shown that PID precede ictal events in vitro and that their spatial distribution in situ is aligned with seizure initiating regions. Our data suggest that a NMDA-dependant, cellular or synaptic plasticity may underly PID emergence during the transition to seizure. Furthermore stimulated PID-like events can initiate ictal-like discharges at their onset site. Possibly seizures are triggered by repeated PID, involving larger groups of neurons than IID, which initiate changes in glutamatergic or GABAergic signaling. One mechanism could be a depolarizing shift in the reversal potential for $\mathrm{Cl}$-mediated GABAergic events 10 since our data shows GABAergic signaling is needed for ictal-like events, even if PID are resistant. Alternatively, or in conjunction, repeated PID may enhance synaptic excitation 12, 13 sufficiently to recruit neurons to an ictal event.

We have described and dissected a novel epileptiform activity in human epileptic tissue in vivo and in vitro. In the subiculum, emerging PID coexist with IID during the transition to seizure and, once established have a role in seizure initiation. These epileptiform transient events are generated by distinct networks. IID are the expression of a basal epileptic defect due to epileptogenic processes. PID, in contrast, are dynamically generated during the transition period and contribute to ictogenesis at the seizure focus. 


\section{ACKNOWLEDGEMENTS}

We gratefully acknowledge financial support from INSERM, the CNRS, the AP$\mathrm{HP}$, the FRM, the FRC, the ANR, the European Community (EPICURE, LSH037315), Spain-France Joint Action (HF2006-0082), the Spanish National Research Council (CSIC 2007201023) and the Spanish Ministry of Innovation and Science (BFU2006-10584-BFI and BFU2009-07989).

We also wish to thank Dr Marion Noulhiane for her help with imaging and statistics Marie-Laure Tanguy for help with statistical analysis, Emmanuel Eugène for his technical assistance, Mario Valderama for software assistance and Dr Lucia Wittner for participating in initial recordings.

\section{AUTHOR CONTRIBUTIONS}

GH, LMP \& RM designed the research.

$\mathrm{GH}, \mathrm{LMP} \& \mathrm{RM}$ performed in vitro experiments.

SC, JP, GH, CA \& MB performed the in vivo work and analysis.

GH, LMP, JP, IC, MLVQ \& RM contributed to data analysis.

$\mathrm{GH} \& \mathrm{RM}$ wrote the paper. 


\section{FIGURE LEGENDS}

Figure 1 lctal discharges generated in the human subiculum.

Convulsants produced patterned ictal discharges restricted to the subiculum.

(a) Multiple extracellular recordings of an ictal event in a slice containing the hippocampus, subiculum and entorhinal cortex. Electrode locations: 1, dentate gyrus; 2, CA2; 3, CA1; 4-5-6, subiculum; 7, presubiculum; 8, entorhinal cortex.

(b) Ictal event structure. An ictal discharge recorded in a $65 \mathrm{mM} \mathrm{HCO}_{3}^{-}$/ $8 \mathrm{mM}$ $\mathrm{K}^{+}$solution. Top trace: pre-ictal discharges (larger events, filled circles) recur before a fast low voltage activity (grey line) at seizure onset followed by rythmic bursts (black line). Seizure onset is indicated by a doted arrow. Middle trace: time frequency representation of the field potential (LFP). Bottom trace: Multiunit activity (MUA) shows recurring pre-ictal discharges of short duration followed by the rapid unpatterned action potential discharges at seizure onset and then by oscillatory bursts.

Figure 2 Interictal, pre-ictal and ictal discharges in intracranial records.

(a) SEEG recording (electrode HipAg1) showing activity of the subiculum and head of the hippocampus at seizure onset. The seizure is preceded by recurring PID (blue circles) and IID (pink circles). It begins (arrow) with fast low voltage activity and continues with oscillatory rhythmic bursts.

(b) Records from multiple electrode contacts on a referential average montage. Traces from contacts with no epileptic activity are shown in green, those with isolated IID in blue and those recording both IID and PID in pink. Left trace: sample of IID (blue circle). Middle trace: sample of PID (pink circle). Right trace: seizure onset (thick arrow). The thin arrow shows an expanded trace from HipAgl contact in a. Seizure onset is highlighted in yellow. Electrodes are identified according to the recorded area (Amyg: amygdala, Hip: hippocampus, TB: temporo-basal, T2: second temporal gyrus, OrFr: orbitofrontal), location (A: anterior, M: median, P: posterior, AP: antero-posterior) and hemisphere ( $\mathrm{g}$ : left, $\mathrm{d}$ : right). The first contact is at the tip of the electrode and the last one as it emerges from the cranium.

(c) Amplitude distribution for all field potentials preceding by 30 minutes a single ictal event showing the distinct amplitudes of IID $(25-125 \mu \mathrm{V})$ and PID (150-500 $\mu \mathrm{V})$.

(e) 3-D reconstruction of electrode contacts from post-implantation MRI showing sites where PID (pink), IID (blue) or no epileptic events (green) were recorded. An arrow highlighted in yellow shows the site of seizure onset. The name of each electrode is shown at the site of emergence from the skull.

Figure 3 Pre-ictal discharges emerge during the transition to ictal-like activity in vitro. 
(a) Extracellular records of the transition to seizure-like activity induced by increased external $\mathrm{HCO}_{3}^{-}(85 \mathrm{mM})$ and $\mathrm{K}^{+}(8 \mathrm{mM})$. El and $\mathrm{E} 2$ are records from two subicular electrodes. Multiunit activity (MUA) frequency (upper trace) and the extracellular signal from E2 (lower trace) are shown.

(b) Amplitude measurements for all field potentials recorded by electrode E2 during the transition show the emergence of larger pre-ictal discharges while the amplitude of inter-ictal events did not change.

(c) Dual extracellular records showing interictal discharges (IID, open circles, left) before convulsant application and co-expression of PID (filled circles, right) with IID during the transition.

(d) Amplitude distribution for all field potentials during the 35 minutes transition

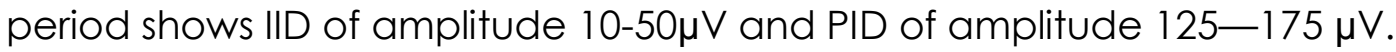

(e) Mean and standard deviation of the amplitude (black), duration (red) and propagation speed (blue) of IID and PID at steady state. Amplitudes and propagation speed but not durations were significantly different (starred line).

(f) Propagation of IID and PID. Triple extracellular recording (E, E2, E3; E1-E2 distance: $1 \mathrm{~mm}$; E2-E3 distance: $0.7 \mathrm{~mm}$; E1-E3 distance: $1.4 \mathrm{~mm}$ ) during the transition to ictal-like events. Field potential (FP) amplitude is plotted from signals from each electrode and the propagation speed of fields during the transition (between El and E3) is shown above. Top traces: initial IID (left), emerging PID (middle) and fully developed PID (right). Grey lines link FP peaks.

Figure 4 Pre-ictal discharges depend on glutamatergic signaling.

(a) Intracellular record from a subicular pyramidal cell (I) with a local extracellular record (E). This cell received hyperpolarizing synaptic inputs during IID (open circle) both before and after convulsants were added. In contrast, it was depolarized during PID (filled circle) in the presence of convulsants. Intracellular action potentials are cut.

(b) IID and PID co-existed during the transition to ictal discharges induced by $0.25 \mathrm{mM} \mathrm{Mg}^{2+}$ and $8 \mathrm{mM} \mathrm{K}^{+}$(left traces). Bicuculline (bic) blocked IID but not PID (middle left). The NMDA receptor blocker D-L APV $(100 \mu \mathrm{M})$ did not change PID (middle right) but the AMPA receptor antagonist NBQX $(10 \mu \mathrm{M})$ suppressed them (right).

(c) Distinct reversal potentials for synaptic events associated with IID and PID. The amplitude of postsynaptic potentials associated with IID (open circles) and PID (filled circles) is plotted against membrane potential during the transition. Data from 3 different cells (black, blue and red). Inset: postsynaptic potentials associated with IID and PID at different membrane potentials. Intracellular (I, upper) and extracellular ( $\mathrm{E}$, lower trace). The mean reversal potential of IID was $-59.1 \pm 3.8 \mathrm{mV}$ and the estimated reversal potential of PID was $-15.1 \pm 5.9 \mathrm{mV}$. 
(d) PID induced by increasing excitability with high $\mathrm{K}^{+}$but no convulsant. Field potentials show co-existing PID (filled circle) and IID (open circle) in $10 \mathrm{mM} \mathrm{K}^{+}$.

Figure $5 \mathrm{NMDA}$ receptor signaling is involved in seizure generation and in the emergence of pre-ictal discharges but not their maintenance.

All extracellular recordings from the same site in the subiculum.

(a) Left trace: spontaneous IID (open circles). The NMDA receptor antagonist, D-APV did not affect IID (middle trace) but when it was present the convulsant solution (10 $\mathrm{mM} \mathrm{K}^{+} / 0.25 \mathrm{mM} \mathrm{Mg}^{2+}$ ) did not induce PID or ictal-like events (right trace).

(b) Left trace: After D-APV washout, the convulsant solution induced PID (filled circles) during the transition period (second trace) to ictal discharges (grey line, third trace). Application of D-APV after PID had emerged did not change them, but suppressed the initiation of ictal-like events (right trace).

Figure 6 Interictal and pre-ictal discharges are generated by distinct networks. Firing of putative pyramidal cells (a) and interneurons (b) recorded juxtacellularly during interictal (IID, blue) and pre-ictal discharges (PID, red). Cell type was attributed from action potential duration (upper traces) measured from the positive to the negative peak (pyramidal cells $>0.7 \mathrm{~ms}$, interneurons $<0.7 \mathrm{~ms}$ ). Spike timing for pyramidal cells and interneurons (shown as dots in the box), spike probability (histograms) and spike frequency (lower traces) are shown with respect to IID and PID field potentials (upper trace). The dotted line with an arrow tail indicates the onset of field potentials and the dotted line with an arrow head its peak.

(a) Most pyramidal cell were inhibited during IID and fired during PID (left) while a subset of pyramidal cells (7/39) fired both during IID and before PID onset (right).

(b) All interneurons fired before IID onset and after PID initiation (left) but some interneurons (2/6) fired before both IID and PID onset.

Figure 7 Dynamics of population activity during the transition to ictal events.

(a) Dual extracellular records during the interictal period (white line), the preictal period (black line) and the onset of an ictal-like event (green line). Interictal events (open circle) and pre-ictal events (filled circle) during the transition are shown below on an expanded time-scale. Time frequency analysis of the extracellular signal is below.

(b) Cross correlation index versus time lag for IID (empty circles) and PID (filled circles).

(c) 3-D plot of the cross correlation index, time lag between sites and the amplitude of the field potential for IID, PID and initial ictal discharges. 
(d) Histograms of the amplitude, time lag and cross correlation index for each type of event. Error bars indicate standard deviations. Lines with a star indicate a significant difference.

Figure 8 Repeated pre-ictal discharges trigger seizure-like events.

(a) Dual extracellular records of an ictal event preceded by PID. The lower black trace was recorded near the site of onset of PID and ictal events. The upper grey record was made from a follower region. Right: expanded traces from the starred period.

(b) Electrical stimulation ( $2 \mathrm{~Hz}, 2$ s; black sign) near the site of PID initiation, elicits PID (expanded at right), which induce a seizure-like event.

(c) Identical electrical stimulation (grey sign) in a region of PID propagation does not trigger seizure-like events.

(d) High intensity bipolar electrical stimulation (large grey sign) in the region of PID propagation generates PID at their initiation site. A seizure like event follows. The double headed arrow indicates the delay between stimulation and back-propagated PID onset.

(e) Probability of triggering an ictal-like event by moderate intensity stimuli at the PID focus (black), at a follower site (white) or by strong stimuli at the follower site generating back-propagated PID (grey). * indicates $p<10^{-6}$, ** indicates $p<10^{-12}$ 


\section{METHODS}

Epileptic tissue.

Temporal lobe tissue blocks containing the hippocampus, subiculum and part of the entorhinal cortex were obtained after operations on 45 people with pharmacoresistant mesial temporal lobe epilepsies associated with hippocampal sclerosis (age 18-52 years, seizures for 3 to 35 years). Surgery consisted in resecting the amygdala, hippocampus, the anterior parahippocampal gyrus and sometimes temporal pole and anterior basal and lateral neocortex. All of them gave their written, informed consent and the 'Comité Consultatif National d'Ethique' approved our protocol.

Stereo electro-encephalographic (SEEG) recordings were performed with depth electrodes to assess seizure onset areas in five subjects before epilepsy surgery (Ad-Tech Medical Instruments, Racine, WI). Signals from electrodes, of diameter $1 \mathrm{~mm}$, with $4-8$ contacts, $1 \mathrm{~mm}$ wide, $2.3 \mathrm{~mm}$ long and $10 \mathrm{~mm}$ apart, were recorded with an EEG video system (Nicolet 6000, Viasys-Nicolet, Madison, WI), sampling 63 iEEG channels at $400 \mathrm{~Hz}$ (bandwidth $0.05-150 \mathrm{~Hz}$ ). Electrode positions were derived from postoperative MRI artifacts. Records were analyzed with Spikoscope and EEG View/LTM software (Nicolet). Seizures and the 3-5 minutes preceding them were analyzed.

\section{Tissue preparation.}

Post-surgical tissue was transported in a cold, oxygenated solution containing d-sucrose, 248; $\mathrm{NaHCO}_{3}, 26 ; \mathrm{KCl}, 1 ; \mathrm{CaCl}_{2}, 1 ; \mathrm{MgCl}_{2}, 10 ; \mathrm{d}$-glucose, $10 \mathrm{mM}$ equilibrated with $5 \% \mathrm{CO}_{2}$ in $95 \% \mathrm{O}_{2}$. Hippocampal-subicular-entorhinal cortex slices or isolated subicular slices of thickness $400 \mu \mathrm{m}$ were cut with a vibratome (HM650V, Microm). They were maintained at $37^{\circ} \mathrm{C}$, equilibrated with $5 \% \mathrm{CO}_{2}$ in $95 \% \mathrm{O}_{2}$, in an interface chamber perfused with a solution containing $\mathrm{NaCl}, 124 ; \mathrm{NaHCO}_{3}, 26 ; \mathrm{KCl}, 4 ; \mathrm{MgCl}_{2}, 2 ; \mathrm{CaCl}_{2}, 2$ and d-glucose, $10 \mathrm{mM}$. NBQX and D,L-APV were used to block glutamatergic signaling and bicuculline or picrotoxin for $G_{A B A}$ receptors. Ictal-like activity was induced either by increasing $\mathrm{NaHCO}_{3}$ to $65-85 \mathrm{mM}$ with a concomitant reduction in $\mathrm{NaCl}$ to $85-65 \mathrm{mM}$, or by reducing $\mathrm{Mg}^{2+}$ to $0.25 \mathrm{mM}$. These changes were coupled with an increase in external $\mathrm{K}^{+}$to 6-8 $\mathrm{mM}$ or, for the high $\mathrm{HCO}_{3}{ }^{-}$/ low $\mathrm{Cl}^{-}$case, a decrease of $\mathrm{Mg}^{2+}$ and $\mathrm{Ca}^{2+}$ to $0.5 \mathrm{mM}$. A stable expression of both IID and PID was induced using a $10 \mathrm{mM} \mathrm{K}^{+}$solution.

\section{Recordings.}

Up to four tungsten electrodes etched to a tip diameter of $\sim 5 \mu \mathrm{m}{ }^{46}$ were used for extracellular recording. Signals were amplified 1000x and filtered to pass frequencies of $0.1 \mathrm{~Hz}$ to $10 \mathrm{kHz}$ (AM systems, 1700).

Intracellular records were made with glass microelectrodes containing $2 \mathrm{M} \mathrm{KAc}$ and beveled to a resistance of 50-100 M $\Omega$. Signals were amplified 
with an Axoclamp 2B amplifier in current clamp mode ${ }^{2}$. Juxtacellular records

${ }^{24}$ were made with glass micro-electrodes of resistance $3-5 \mathrm{M} \Omega$ filled with the perfusion solution.

Intracellular and extracellular signals were digitized at $10 \mathrm{kHz}$ with a 12bit, 16-channel A-D converter (Digidata 1200A, Axon Instruments), monitored and saved to a PC with the program Axoscope (Axon Instruments).

Data analysis.

Recordings were analyzed with Clampfit (Axon Instruments), Spikoscope (http://spikoscope.sourceforge.net) software and routines written in LabView (National Instruments, Austin, TX), Spikoscope and Matlab (MathWorks).

Extracellular records were filtered post-hoc to display action potentials or field events ${ }^{46}$. Field potential events, including interictal and pre-ictal events, were detected with an 'up-only' algorithm and a user-defined threshold.

The dynamics of changes in extracellular signals at the transition to ictal-like discharges were computed from normalized cross-correlations between extracellular records using the fast Fourier transform (1024 points Hanning window, mean detrending). Synchronization dynamics was estimated with a sliding cross-correlogram (moving window: 350ms, overlap: $345 \mathrm{~ms}$ ) or a fixed window cross-correlation (window: $350 \mathrm{~ms}$ ). Latencies between pairs of records were calculated from the peak offset of the crosscorrelation function.

Extracellular records were low pass filtered $(500 \mathrm{~Hz}$, zero-phase shift) to detect changes in field potentials during the transition to ictal-like activity. The amplitude and timing of all detected field events was measured and independent time series were constructed for IID and PID after a twothreshold separation based on amplitude. The timing of PID measured at different periods during the transition was used as a reference. Typically 5 to 15 IID occurring before and after PID were plotted against amplitude and inter-event interval.

Juxtacellularly recorded action potentials were correlated with a local field potential. Cells firing juxtracellular spikes with less than $0.7 \mathrm{~ms}$ between their positive and negative peaks 47,48 were presumed to be interneurons. Spikes were detected using a threshold detection algorithm (>5:1 signal to noise ratio). Temporal relations between single spikes and interictal discharges (IID or PID) were examined by aligning all individual field discharges on their maxima and constructing discharge-triggered spike histograms. The instantaneous spike frequency was measured by convolving the timing of each detected event with a Gaussian function of $20 \mathrm{~ms}$ standard deviation. A significant change in spike frequency was defined as an absolute fluctuation over 3 SD of the baseline firing and was defined relative to the time of field maxima. 
Time-frequency analyses were performed using a wavelet transform ${ }^{49}$.

Statistics.

The JMP 7.2 software (SAS Institute Inc, Cary, NC, USA) was used and results expressed as mean $\pm S D$ with significance of $P<0.05$. Exact $p$ values are given unless $p<0.0001$. Distributions were described by $95 \%$ Confidence Intervals $(\mathrm{Cl})$ or median and range values when $\mathrm{n}<10$. Fisher's exact test was used to compare small samples. Nonparametric Kruskal-Wallis analysis of variance was used to compare non-homogeneously distributed data. Then, post hoc nonparametric Mann-Whitney rank sum test was performed to test differences between groups. For related samples, the nonparametric Friedmann test was used. For repeated measures ANOVA on ranks and the nonparametric Wilcoxon signed rank test were used. 


\section{REFERENCES}

1. Cohen, I., Navarro, V., Clemenceau, S., Baulac, M. \& Miles, R. On the origin of interictal activity in human temporal lobe epilepsy in vitro. Science 298, 1418-1421 (2002).

2. Huberfeld, G., et al. Perturbed chloride homeostasis and GABAergic signaling in human temporal lobe epilepsy. J Neurosci 27, 9866-9873 (2007).

3. de Curtis, M. \& Avanzini, G. Interictal spikes in focal epileptogenesis. Prog Neurobiol 63, 541-567 (2001).

4. Lehnertz, K., Le Van Quyen, M. \& Litt, B. Seizure prediction. in Epilepsy: A Comprehensive Textbook (ed. J. Engel, Jr.) (Lippincott Williams \& Wilkins, 2007).

5. Avoli, M., et al. Synchronous GABA-mediated potentials and epileptiform discharges in the rat limbic system in vitro. J Neurosci 16, 39123924 (1996).

6. Gnatkovsky, V., Librizzi, L., Trombin, F. \& de Curtis, M. Fast activity at seizure onset is mediated by inhibitory circuits in the entorhinal cortex in vitro. Ann Neurol 64, 674-686 (2008).

7. Miles, R. \& Wong, R.K. Single neurones can initiate synchronized population discharge in the hippocampus. Nature 306, 371-373 (1983).

8. Ziburkus, J., Cressman, J.R., Barreto, E. \& Schiff, S.J. Interneuron and pyramidal cell interplay during in vitro seizure-like events. J Neurophysiol 95, 3948-3954 (2006).

9. Alger, B.E. \& Nicoll, R.A. Pharmacological evidence for two kinds of GABA receptor on rat hippocampal pyramidal cells studied in vitro. J Physiol 328, 125-141 (1982).

10. Kaila, K., Lamsa, K., Smirnov, S., Taira, T. \& Voipio, J. Long-lasting GABAmediated depolarization evoked by high-frequency stimulation in pyramidal neurons of rat hippocampal slice is attributable to a network-driven, bicarbonate-dependent K+ transient. J Neurosci 17, 7662-7672 (1997).

11. Staley, K.J., Soldo, B.L. \& Proctor, W.R. Ionic mechanisms of neuronal excitation by inhibitory GABAA receptors. Science 269, 977-981 (1995).

12. Derchansky, M., et al. Transition to seizures in the isolated immature mouse hippocampus: a switch from dominant phasic inhibition to dominant phasic excitation. J Physiol 586, 477-494 (2008).

13. Trevelyan, A.J., Sussillo, D., Watson, B.O. \& Yuste, R. Modular propagation of epileptiform activity: evidence for an inhibitory veto in neocortex. J Neurosci 26, 12447-12455 (2006).

14. Dzhala, V.I. \& Staley, K.J. Transition from interictal to ictal activity in limbic networks in vitro. J Neurosci 23, 7873-7880 (2003).

15. Jensen, M.S. \& Yaari, Y. Role of intrinsic burst firing, potassium accumulation, and electrical coupling in the elevated potassium model of hippocampal epilepsy. J Neurophysiol 77, 1224-1233 (1997).

16. Bartolomei, F., Chauvel, P. \& Wendling, F. Epileptogenicity of brain structures in human temporal lobe epilepsy: a quantified study from intracerebral EEG. Brain 131, 1818-1830 (2008). 
17. Bartolomei, F., et al. Pre-ictal synchronicity in limbic networks of mesial temporal lobe epilepsy. Epilepsy Res 61, 89-104 (2004).

18. Spencer, S.S., Guimaraes, P., Katz, A., Kim, J. \& Spencer, D. Morphological patterns of seizures recorded intracranially. Epilepsia 33, 537545 (1992).

19. Bragin, A., Azizyan, A., Almajano, J., Wilson, C.L. \& Engel, J., Jr. Analysis of chronic seizure onsets after intrahippocampal kainic acid injection in freely moving rats. Epilepsia 46, 1592-1598 (2005).

20. Gavaret, M., Badier, J.M., Marquis, P., Bartolomei, F. \& Chauvel, P. Electric source imaging in temporal lobe epilepsy. J Clin Neurophysiol 21, 267282 (2004).

21. Lachaux, J.P., Rudrauf, D. \& Kahane, P. Intracranial EEG and human brain mapping. J Physiol Paris 97, 613-628 (2003).

22. Clark, K.A. \& Collingridge, G.L. Synaptic potentiation of dualcomponent excitatory postsynaptic currents in the rat hippocampus. J Physiol 482 ( $\mathrm{P \dagger}$ 1), 39-52 (1995).

23. Bartho, P., et al. Characterization of neocortical principal cells and interneurons by network interactions and extracellular features. J Neurophysiol 92, 600-608 (2004).

24. Pinault, D. A novel single-cell staining procedure performed in vivo under electrophysiological control: morpho-functional features of juxtacellularly labeled thalamic cells and other central neurons with biocytin or Neurobiotin. J Neurosci Methods 65, 113-136 (1996).

25. Wennberg, R., Arruda, F., Quesney, L.F. \& Olivier, A. Preeminence of extrahippocampal structures in the generation of mesial temporal seizures: evidence from human depth electrode recordings. Epilepsia 43, 716-726 (2002).

26. Fabo, D., et al. Properties of in vivo interictal spike generation in the human subiculum. Brain 131, 485-499 (2008).

27. Staba, R.J., et al. High-frequency oscillations recorded in human medial temporal lobe during sleep. Ann Neurol 56, 108-115 (2004).

28. Gabriel, S., et al. Stimulus and potassium-induced epileptiform activity in the human dentate gyrus from patients with and without hippocampal sclerosis. J Neurosci 24, 10416-10430 (2004).

29. Jandova, K., et al. Carbamazepine-resistance in the epileptic dentate gyrus of human hippocampal slices. Brain 129, 3290-3306 (2006).

30. D'Antuono, M., et al. GABAA receptor-dependent synchronization leads to ictogenesis in the human dysplastic cortex. Brain 127, 1626-1640 (2004).

31. Spencer, S.S., Kim, J., deLanerolle, N. \& Spencer, D.D. Differential neuronal and glial relations with parameters of ictal discharge in mesial temporal lobe epilepsy. Epilepsia 40, 708-712 (1999).

32. Bartolomei, F., et al. Entorhinal cortex involvement in human mesial temporal lobe epilepsy: an electrophysiologic and volumetric study. Epilepsia 46, 677-687 (2005). 
33. Khalilov, I., Holmes, G.L. \& Ben-Ari, Y. In vitro formation of a secondary epileptogenic mirror focus by interhippocampal propagation of seizures. Nat Neurosci 6, 1079-1085 (2003).

34. Derchansky, M., et al. Model of frequent, recurrent, and spontaneous seizures in the intact mouse hippocampus. Hippocampus 14, 935-947 (2004).

35. Avoli, M., et al. Network and pharmacological mechanisms leading to epileptiform synchronization in the limbic system in vitro. Prog Neurobiol 68, 167-207 (2002).

36. McGonigal, A., et al. Stereoelectroencephalography in presurgical assessment of MRI-negative epilepsy. Brain 130, 3169-3183 (2007).

37. Chabardes, S., et al. The temporopolar cortex plays a pivotal role in temporal lobe seizures. Brain 128, 1818-1831 (2005).

38. Ebersole, J.S. \& Pacia, S.V. Localization of temporal lobe foci by ictal EEG patterns. Epilepsia 37, 386-399 (1996).

39. Chassoux, F., et al. Intralesional recordings and epileptogenic zone in focal polymicrogyria. Epilepsia 49, 51-64 (2008).

40. Wittner, L. \& Miles, R. Factors defining a pacemaker region for synchrony in the hippocampus. J Physiol (2007).

41. Menendez de la Prida, L, Suarez, F. \&Pozo, M. A. Electrophysiological and morphological diversity of neurons from the rat subicular complex in vitro. Hippocampus 13, 728-44 (2003).

42. Miles, R., Traub, R.D. \& Wong, R.K. Spread of synchronous firing in longitudinal slices from the CA3 region of the hippocampus. J Neurophysiol 60, 1481-1496 (1988).

43. Bragin, A., Azizyan, A., Almajano, J. \& Engel, J., Jr. The cause of the imbalance in the neuronal network leading to seizure activity can be predicted by the electrographic pattern of the seizure onset. J Neurosci 29, 3660-3671 (2009).

44. Traynelis, S.F. \& Dingledine, R. Potassium-induced spontaneous electrographic seizures in the rat hippocampal slice. J Neurophysiol 59, 259276 (1988).

45. Trevelyan, A.J., Sussillo, D. \& Yuste, R. Feedforward inhibition contributes to the control of epileptiform propagation speed. J Neurosci 27, 3383-3387 (2007).

46. Cohen, I. \& Miles, R. Contributions of intrinsic and synaptic activities to the generation of neuronal discharges in in vitro hippocampus. J Physiol 524 Pt 2, 485-502 (2000).

47. Henze, D.A., et al. Intracellular features predicted by extracellular recordings in the hippocampus in vivo. J Neurophysiol 84, 390-400 (2000).

48. Le Van Quyen, M., et al. Cell type-specific firing during ripple oscillations in the hippocampal formation of humans. J Neurosci 28, 6104-61 10 (2008).

49. Le Van Quyen, M. \& Bragin, A. Analysis of dynamic brain oscillations: methodological advances. Trends Neurosci 30, 365-373 (2007). 
a
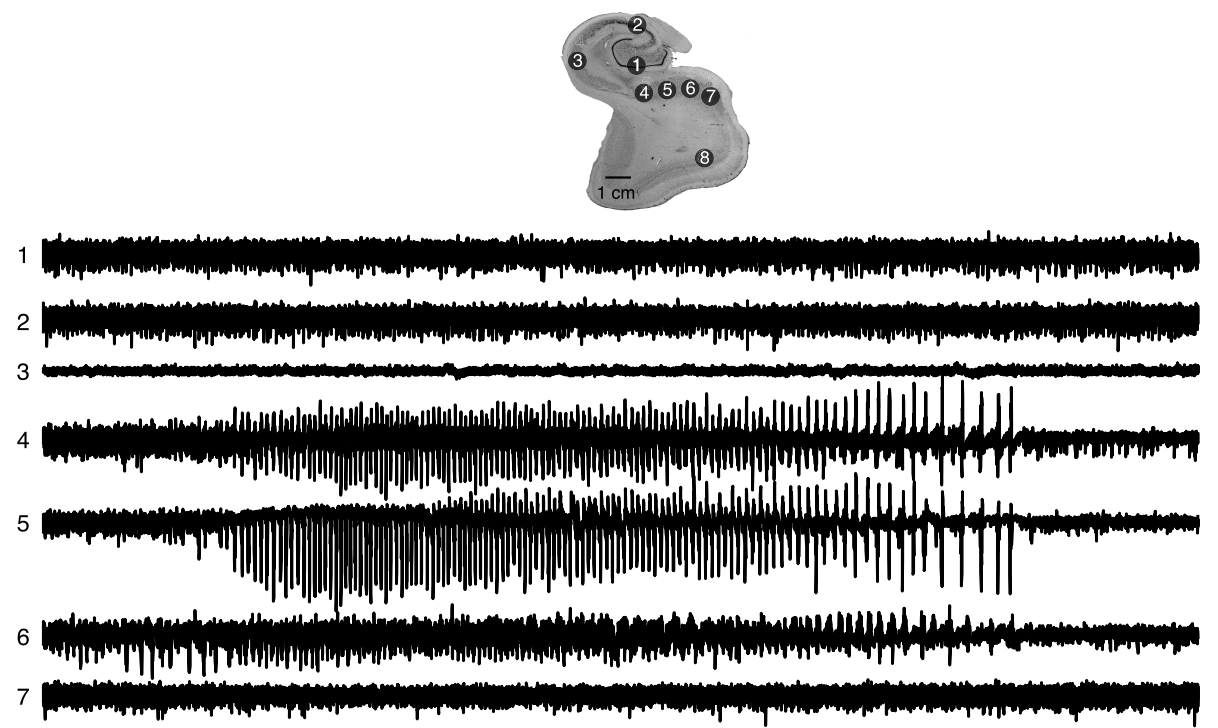

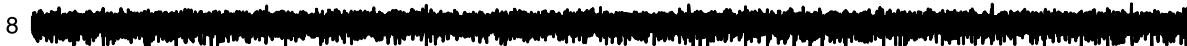
$500 \mu \mathrm{V}$ $5 \mathrm{~s}$

b

Raw

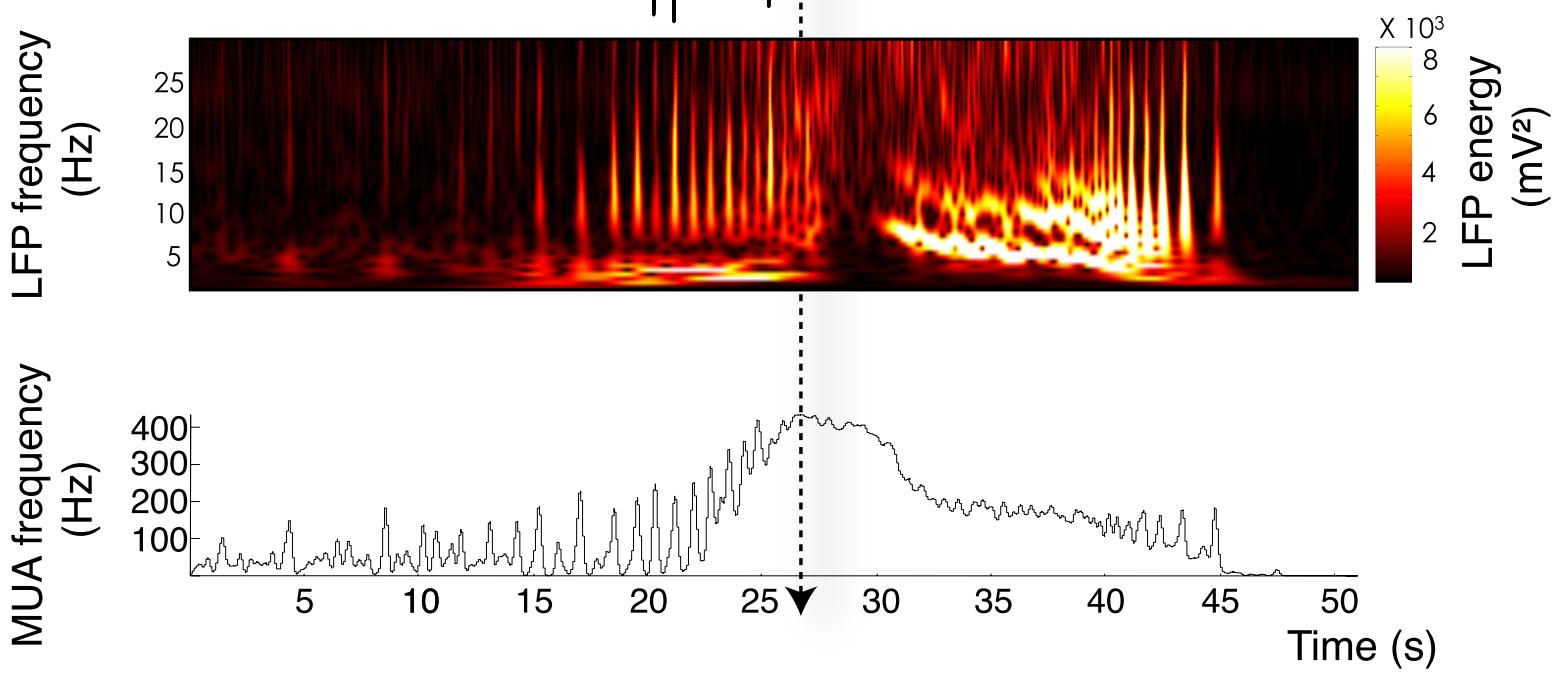


a

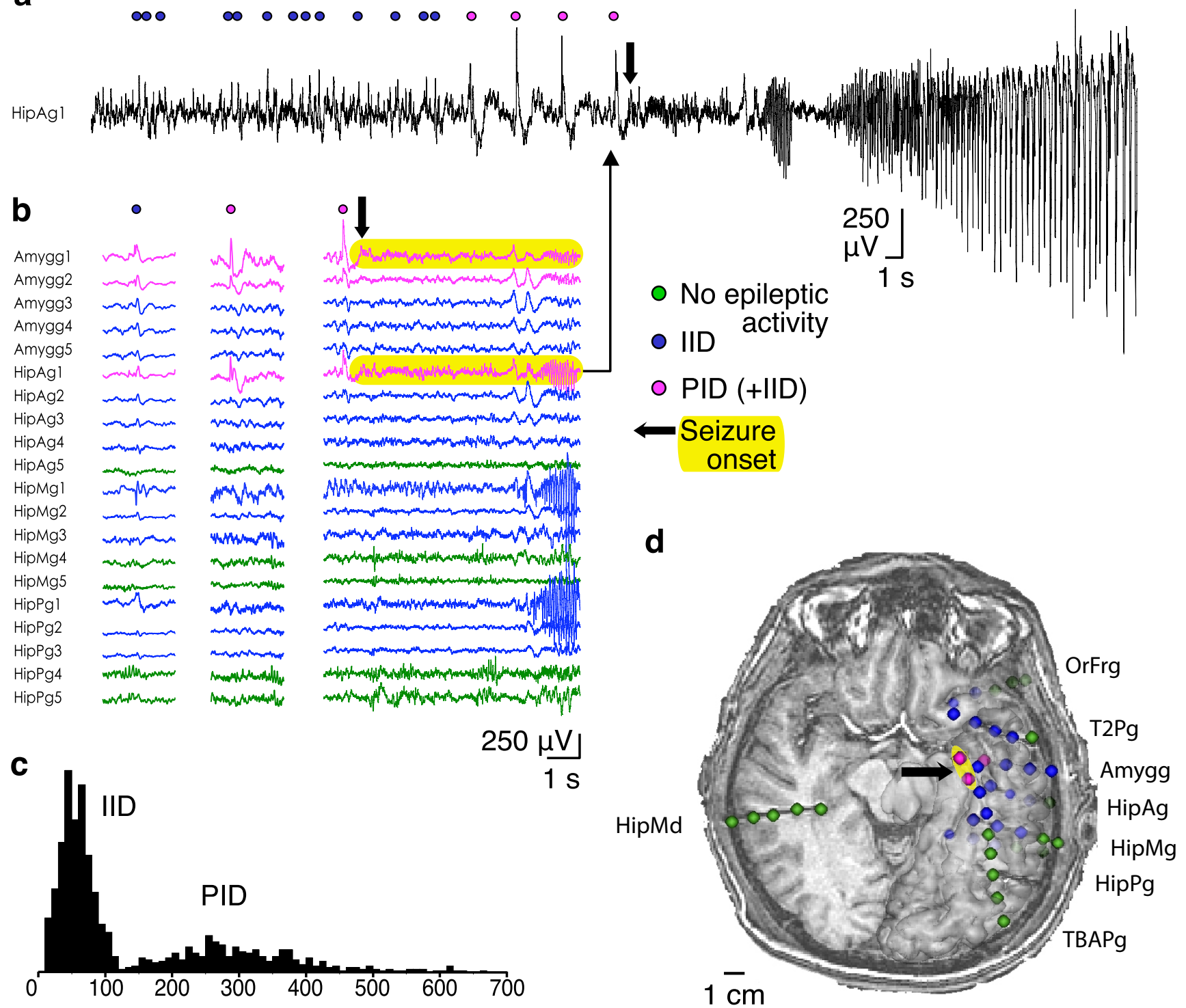
Amplitude distribution $(\mu \mathrm{V})$ 
a

E2 MUA

frequency

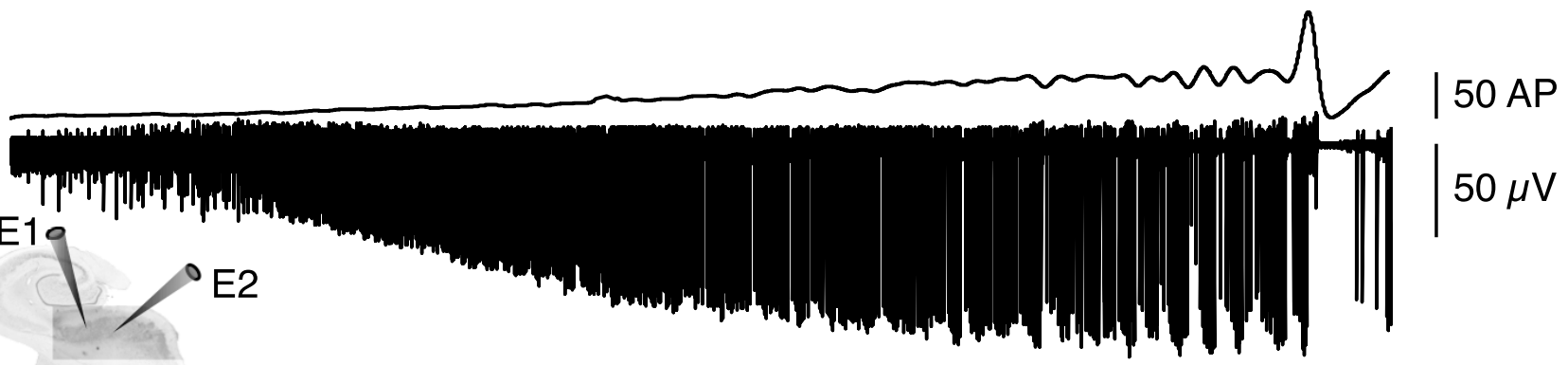

b

E2 FP amplitude

C<smiles>[3H][3H]</smiles>

E1

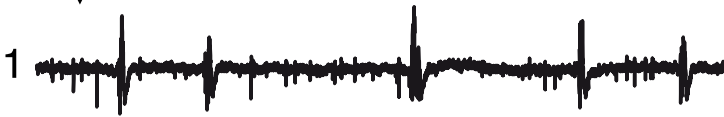

O 0

$0 \quad 0 \quad \infty$

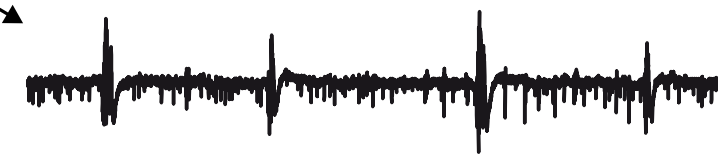

E2 mony

O IID

- PID

d

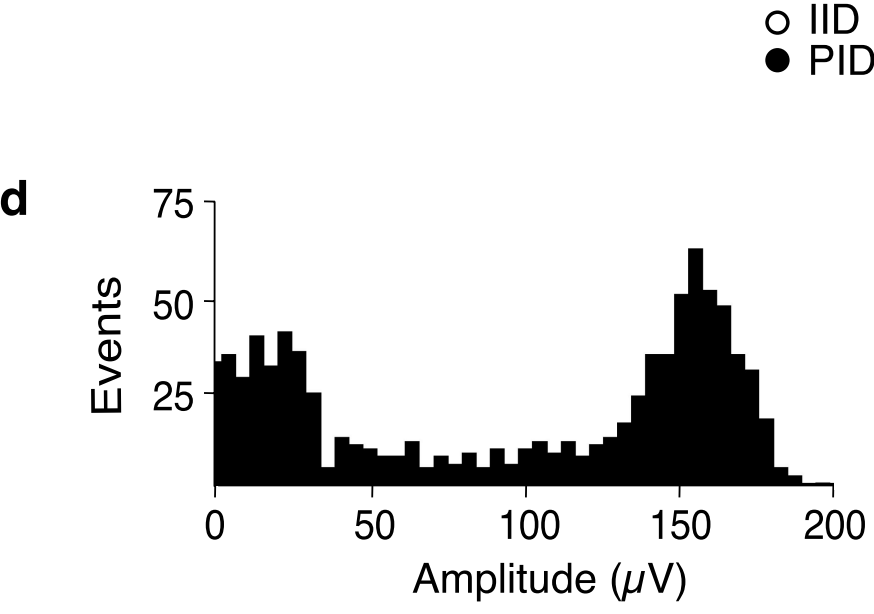

e

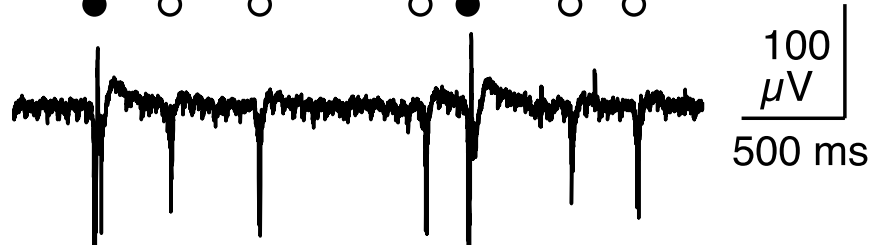
- $50 \mu \mathrm{V}$ $1 \mathrm{~m}$
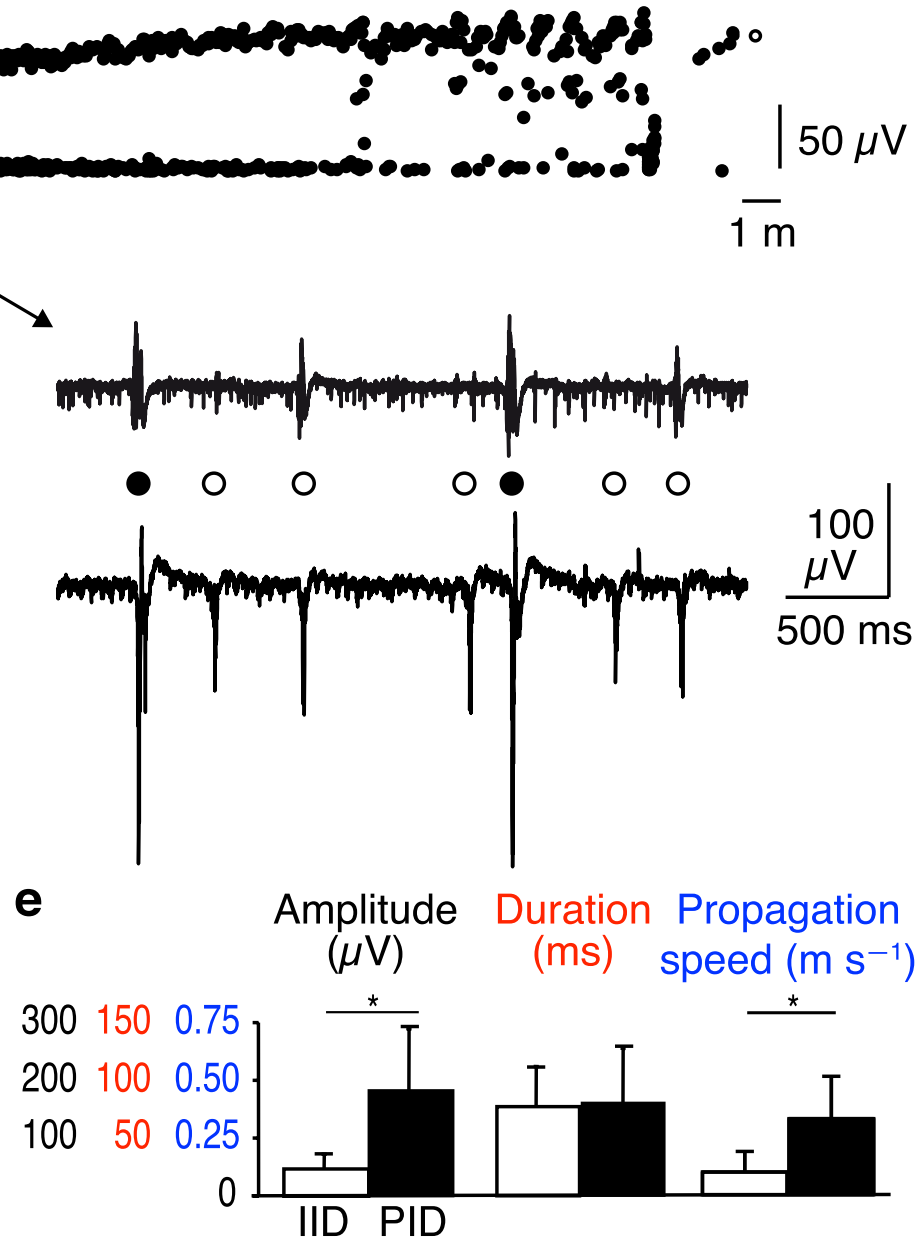

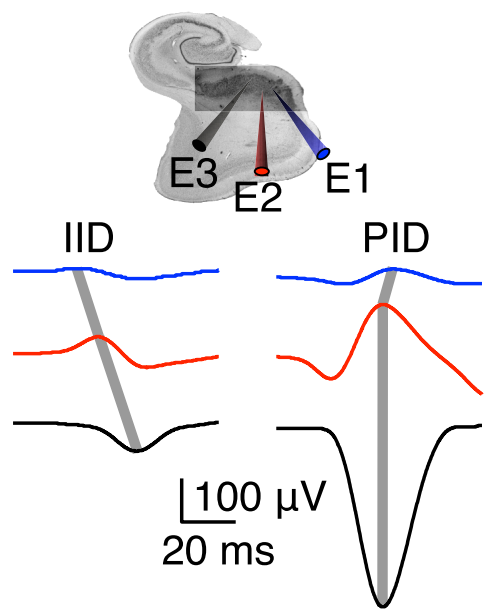

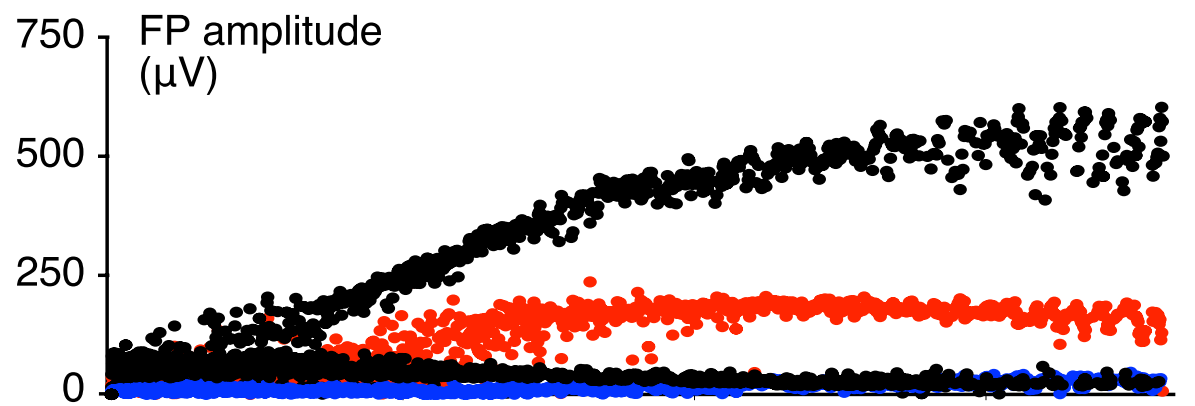

1.0 E1-E3 FP propagation speed $\left(\mathrm{m} \mathrm{s}^{-1}\right)$

0.5

\section{$\circ 00^{\circ}$} $\log ^{\infty}$

10

20 
a

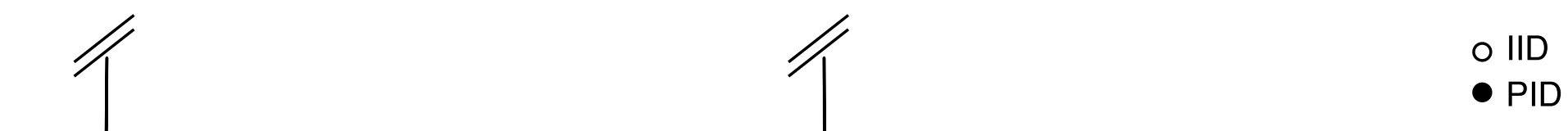

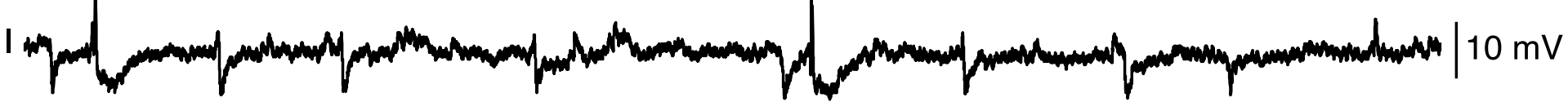

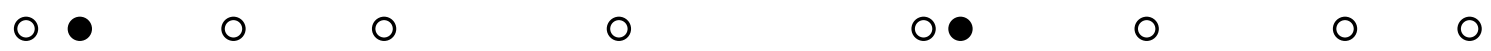

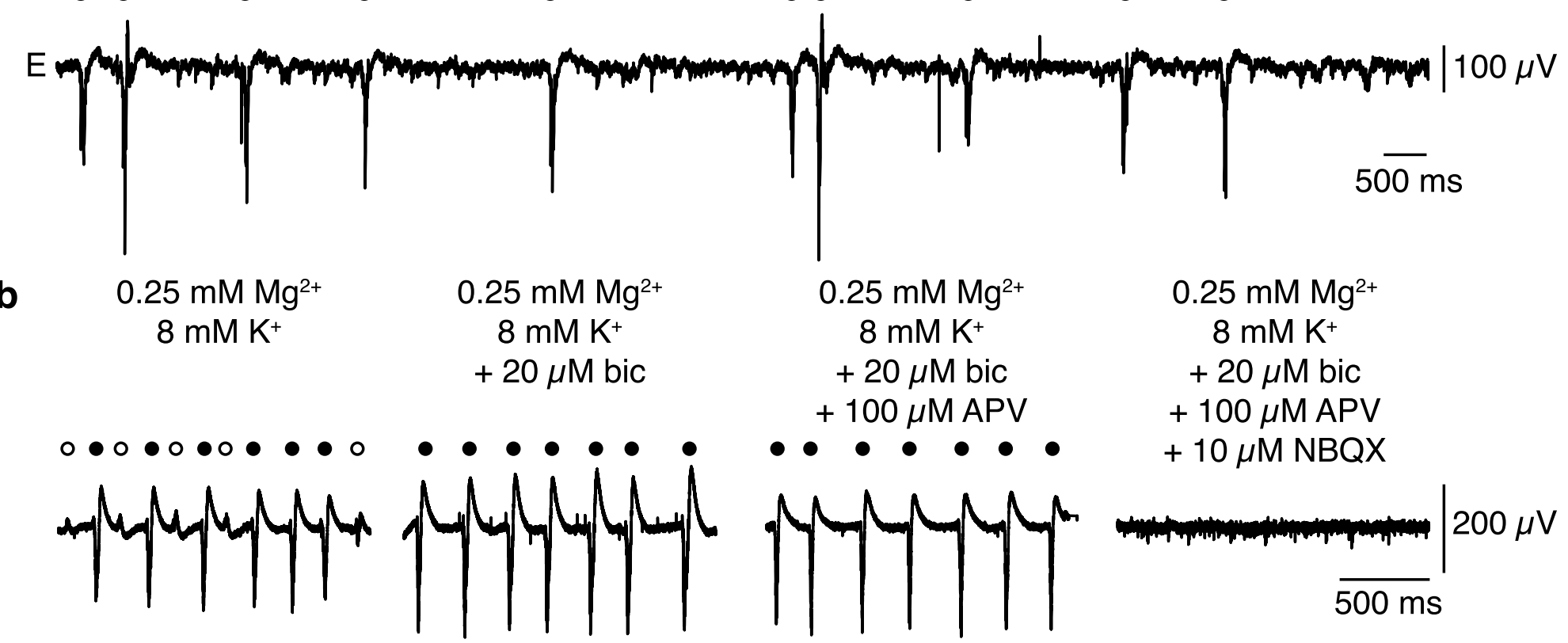

C
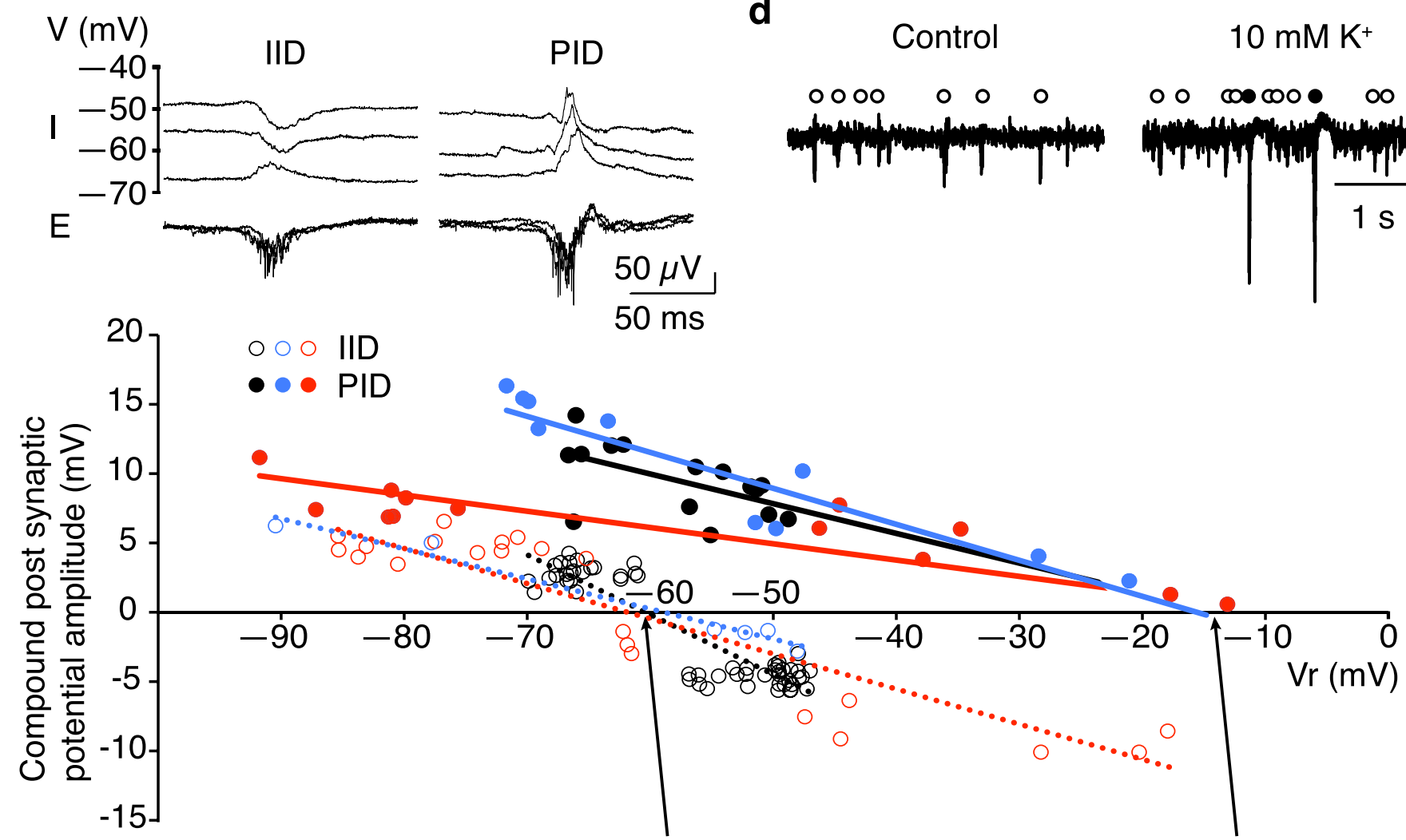

Mean IID reversal potential: $-59.1 \mathrm{mV}$ Mean PID reversal potential: $-15.1 \mathrm{mV}$ 
a Control

$$
\text { D-L-AP5 } 100 \mu \mathrm{M}
$$
(60 min)
D-L-AP5 $100 \mu \mathrm{M}$

$\mathrm{K}^{+} 10 \mathrm{mM} / \mathrm{Mg}^{2+} 0.25 \mathrm{mM}$

(60 min)

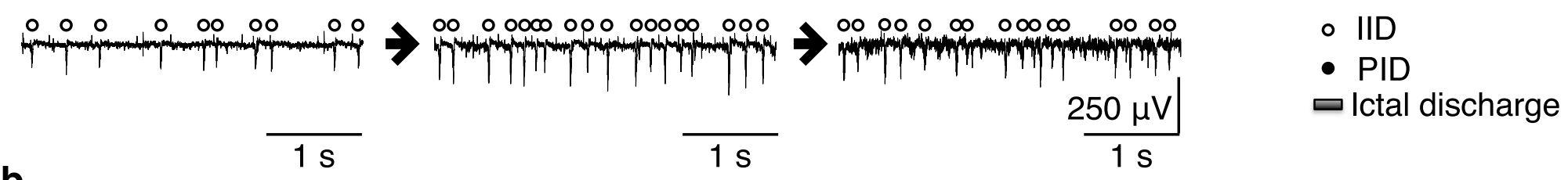

b

Control

(60 min washout)
$\mathrm{K}^{+} 10 \mathrm{mM} / \mathrm{Mg}^{2+} 0.25 \mathrm{mM}$ (30 min)
$\mathrm{K}^{+} 10 \mathrm{mM} / \mathrm{Mg}^{2+} 0.25 \mathrm{mM}$ (60 min)

$\mathrm{K}^{+} 10 \mathrm{mM} / \mathrm{Mg}^{2+} 0.25 \mathrm{mM}$ D-L-AP5 $100 \mu \mathrm{M}$ (60 min)
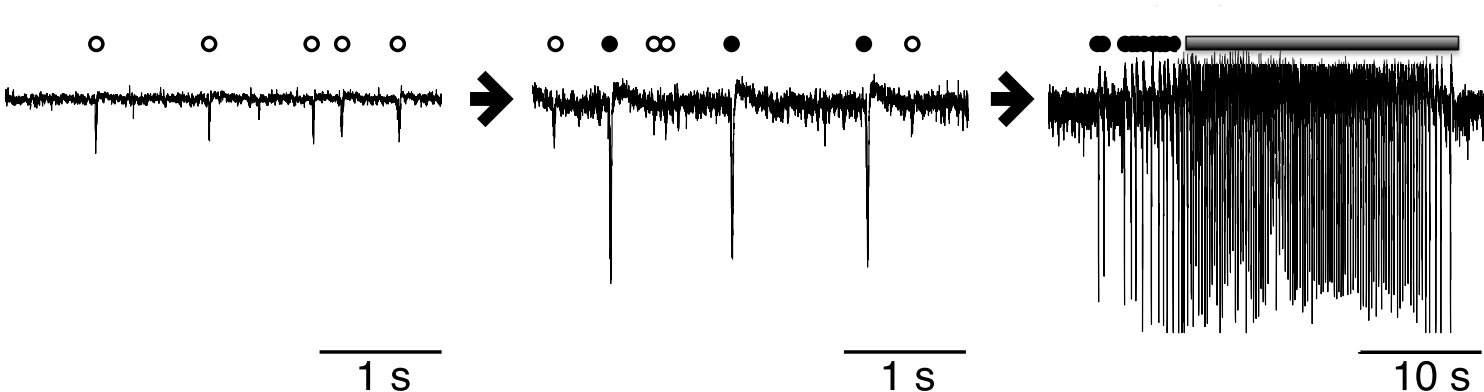

०० 0 • 0

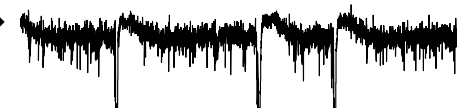


a Pyramidal cells
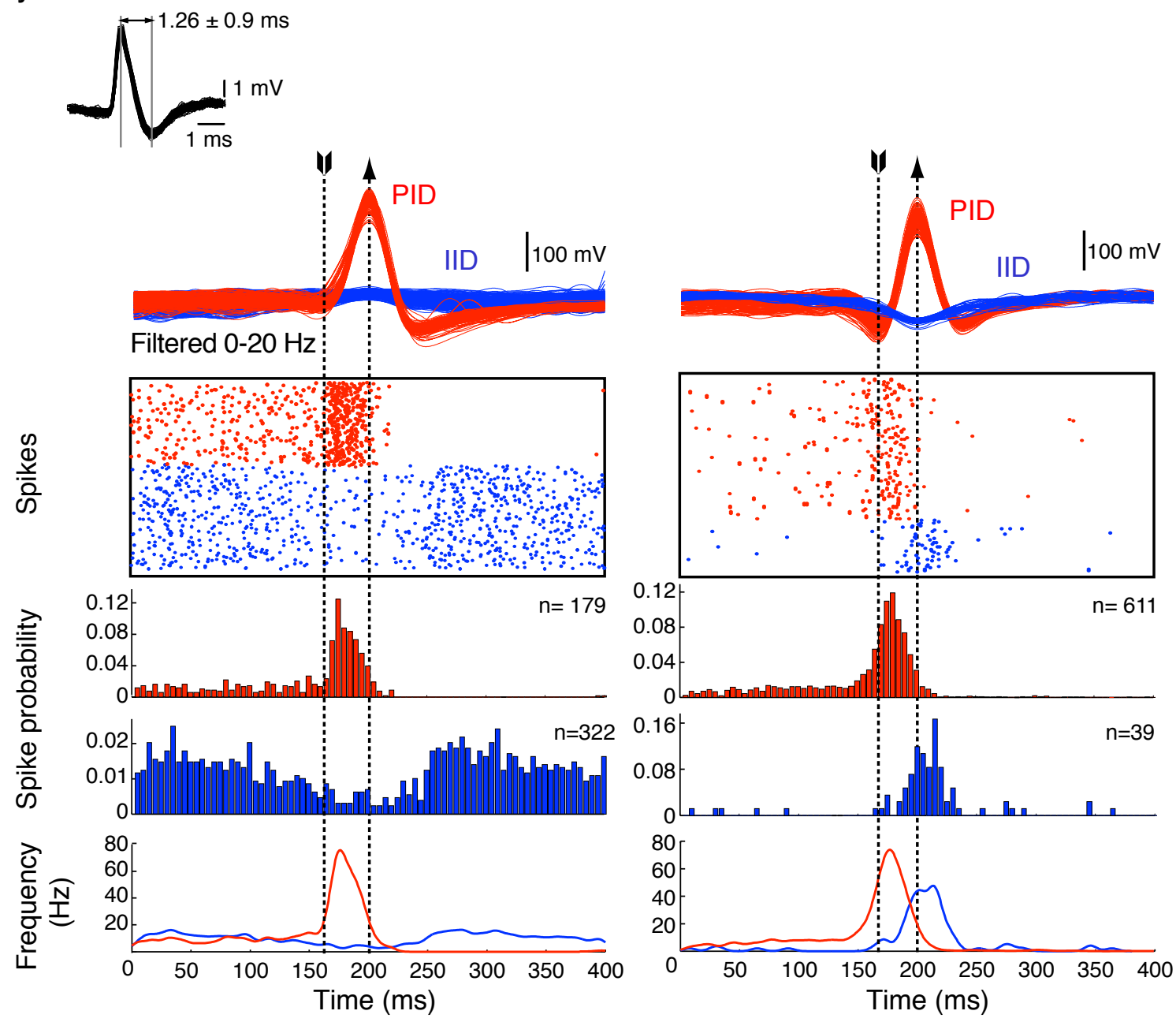

b Interneurons
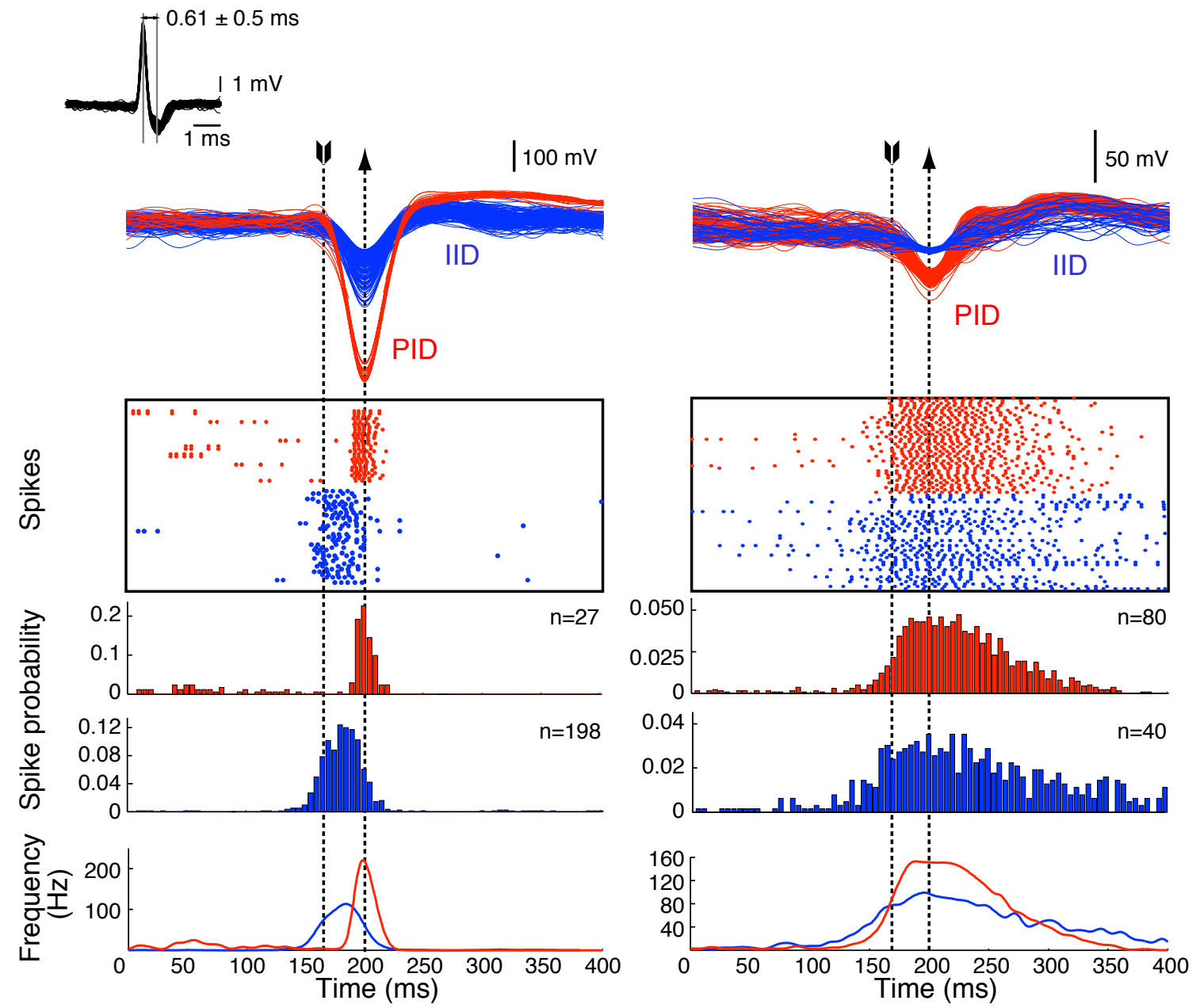


\section{a}

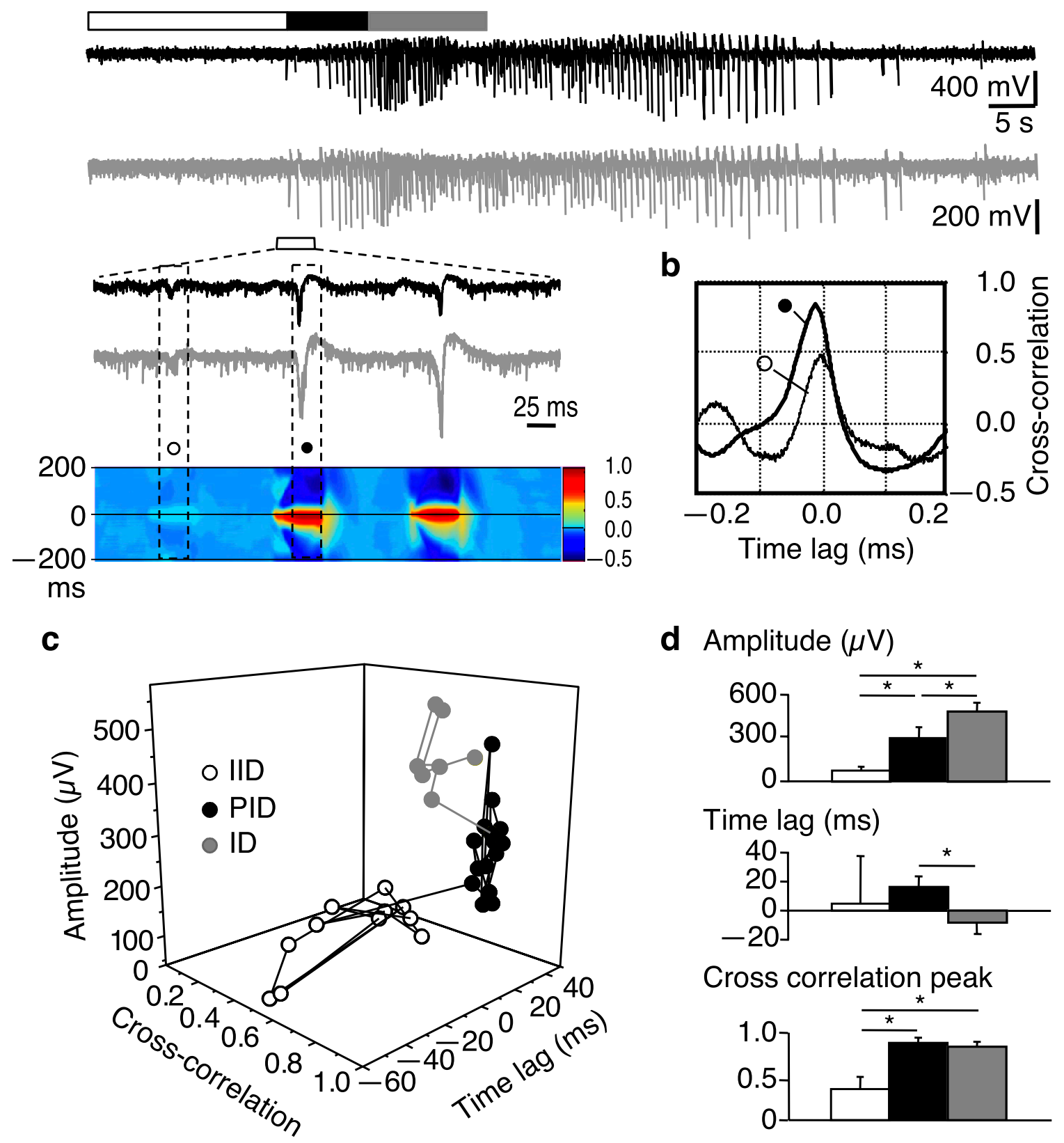


a
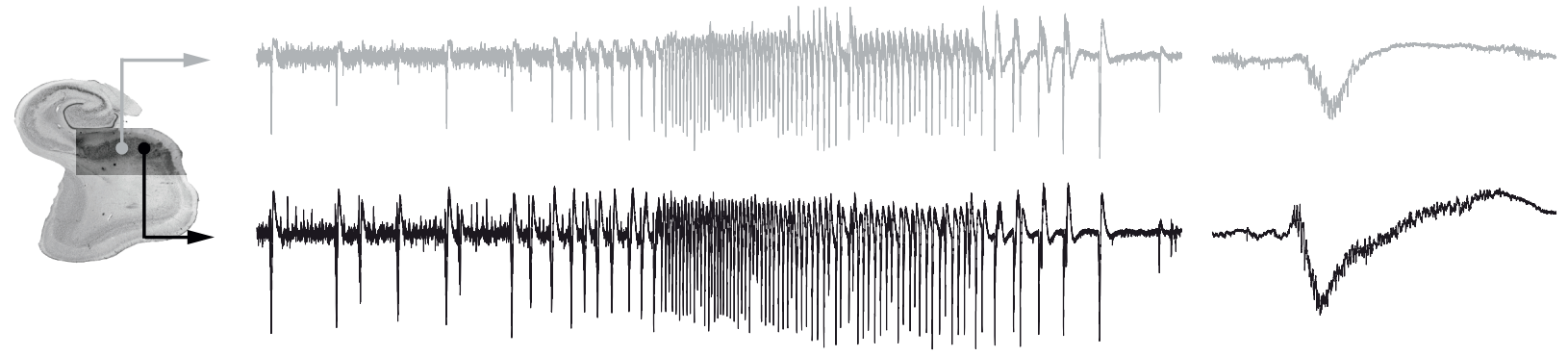

b

$\star$

*
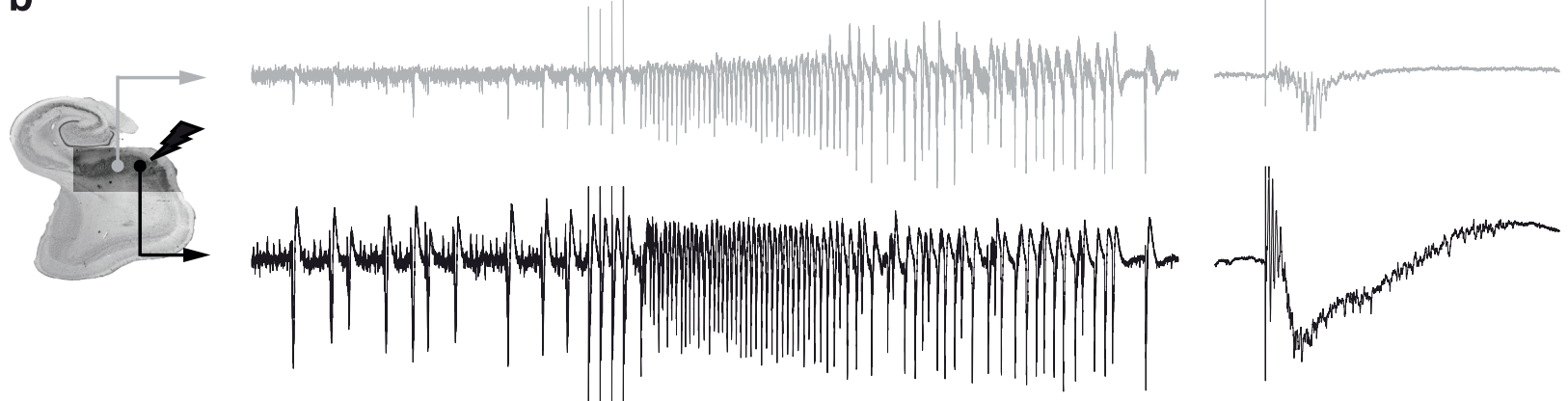

C

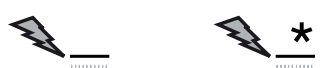

$\star$
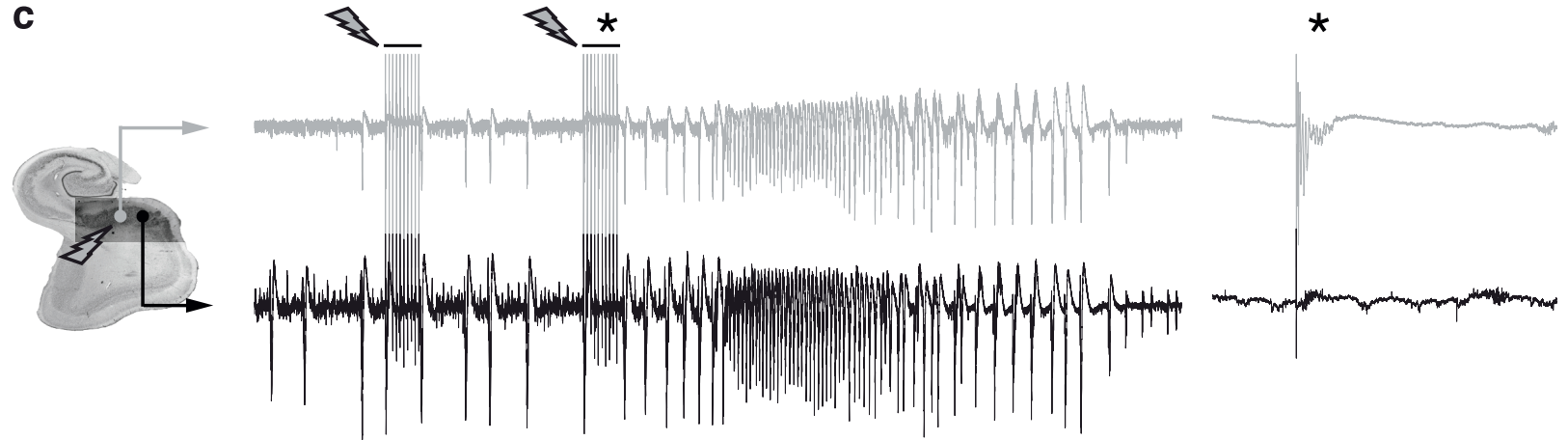

d

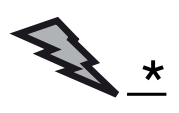

*
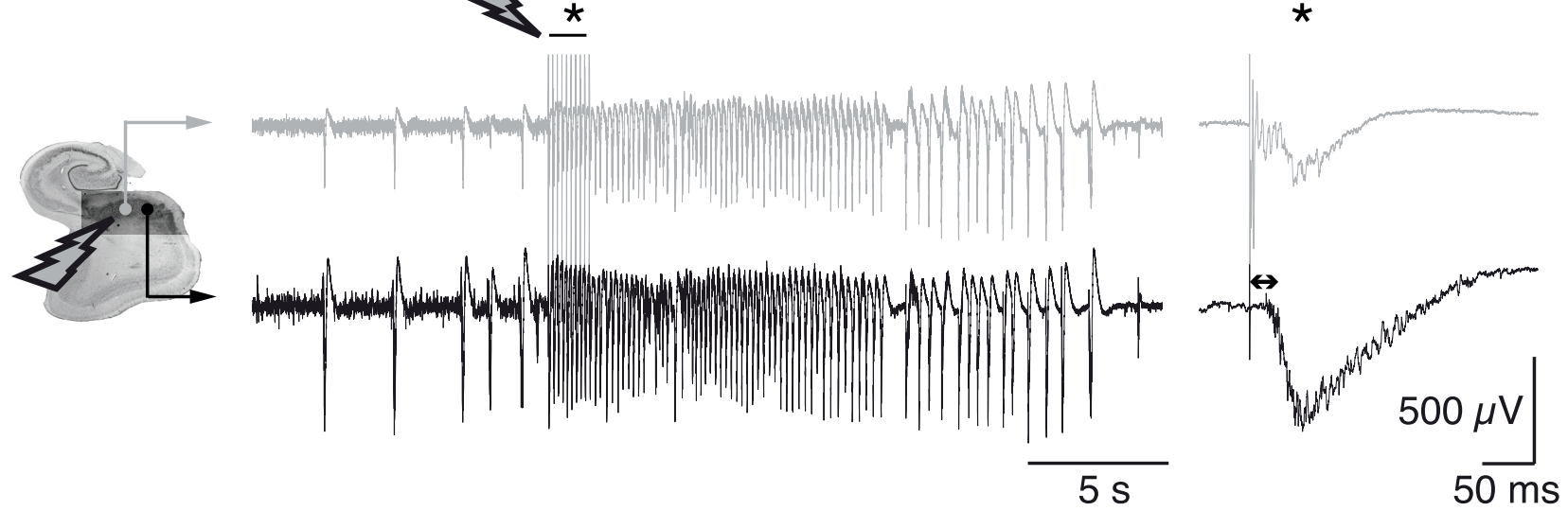

e

Seizure trigger probability

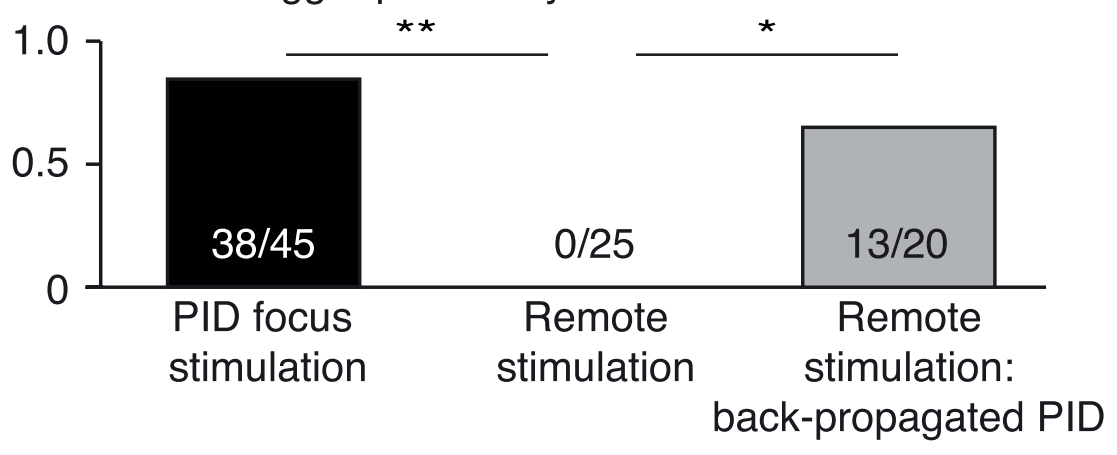

